\title{
ASPECTOS GEOLÓGICOS DOS LATERITOS DA AMAZÔNIA
}

\author{
MARCONDES L.COSTA*
}

\begin{abstract}
GEOLOGICAL ASPECTS OF THE AMAZON LATERITES. Lateritic rocks are widely found all over the Amazon region. They include mature and immature autochthonous laterites and allochthonous laterites, the latter usually reffered to as stone lines. The mature laterites were formed in the Tertiary, while the immature in the Quaternary. The mature laterites are characterized by well-defined and varied horizon when compared to immature laterite profiles. The parent rocks are of different ages and their petrochemical compositions have given rise to different kinds of laterites. among which the most prominent are the bauxitic, the phosphatic, the ferruginous, the caolinic, the manganesiferous and the nickelliferous. The outtermost cover is called Belterra Clay, a yellow clay material, originated from the lateritic profile weathering. Non-lateritic ironstones are common in the region, sometimes associated with the lateritic profiles. Besides their significant ore potentiality for iron, aluminium, nickel, gold, manganese, phosphates, kaolin, titanium, niobium and REE, laterites are important tools for geochemical exploration, geological mapping and also for geological and geomorphological studies of the evolution of the Amazon region.
\end{abstract}

Keywords: Mature laterites, immature laterites, lateritic mineralization, weathering.

RESUMO Rochas lateríticas se encontram distribuídas por toda a região Amazônica. Elas envolvem lateritos autóctones imaturos e maturos, além daqueles alóctones denominados de "linhas de pedras". Os lateritos maturos formaram-se no Terciário, enquanto os imaturos estabeleceram-se no Quaternário. Os lateritos maturos se caracterizam por perfis melhor diferenciados em horizontes do que os imaturos. As rochas geradoras são de diferentes idades e composições petroquímicas, e produziram diversos tipos de lateritos, com destaque maior para os bauxíticos, os fosfáticos, os ferruginosos, os cauliníticos, os manganesíferos e os niquelíferos. A cobertura mais comum é do tipo Argila de Belterra, representada por material de aspecto argiloso e amarelo, proveniente do intemperismo de pefis lateríticos. Pedras de ferro não-lateríticas são comuns na região, dentro dos perfis lateríticos ou não. Além de seu potencial mineral significativo, os lateritos se apresentam como importante ferramenta para a prospecção geoquímica, para o mapeamento geológico e para o estudo da evolução geológica e geomorfológica da região.

Palavras-chaves: Lateritos maturos, lateritos imaturos, mineralizações lateríticas, intemperismo.

INTRODUÇÃO Nos últimos seis anos, a comunidade geológica brasileira vem se interressando cada vez mais pelo estudo dos lateritos da região amazônica. Tal interesse tem se intensificado devido a sua grande potencialidade mineral $e$ por ser o material geológico que geralmente está aflorando, constituindo-se assim o material de amostragem para a prospecção mineral na região. Este autor vem acompanhando passo-a-passo este desenvolvimento, e tem inclusive participado do treinamento técnico-científico de profissionais deste novo campo de pesquisa.

As primeiras ocorrências de lateritos na região foram feitas por Katzer (1903), que os descreveu como arenitos ferruginosos, aos quais deu a denominação de "Grés do Pará", Shaw et ai. (1925) noticiaram a ocorrência de bauxita fosforosa em Trauira e Pirocaua (Maranhão). Brandt (1932) fez uma descrição mineralógica e petrográfica, e discutiu a génese da bauxita fosforosa de Trauira, enfatizando o papel da lateritização.

Mas foi somente nos anos 50 que se iniciou a descoberta dos grandes depósitos de bauxitas lateríticas da região, como consequência das pesquisas realizadas para este fim pela Kaiser Aluminium Company na região do Baixo Amazonas, e pela Rio Tinto Zinc Company em Paragominas. As primeiras e mais importantes pesquisas regionais sobre bauxitas foram divulgadas por Towse \& Vinson (1959); Guerra (1965), que estudou os lateritos do Acre; por Sombroek (1966), que identificou plintitos, plintitos fósseis e latossolos como lateritos; e Valarelli (1967), que estudou os lateritos manganesíferos da Serra do Navio. Na década de 70, vários trabalhos científicos foram publicados sobre as bauxitas do Baixo Amazonas, Paragominas e Carajás, com destaque para Wolf
(1972), Assad \& Neto (1976), Dennen \& Norton (1977), Greig (1977), Klammer (1978), Assad (1978), Assad \& Beisiegel (1978), Grubb (1979) e Kronberg et al (1979a). Bernardelli \& Beisiegel (1978) descreveram o minério manganesífero laterítico do Azul em Carajás. Em meados da década de 70, o Centro de Geociências da Universidade Federal do Pará iniciou as pesquisas de lateritos, estudando os fosfatos aluminosos da região do Gurupi, naquela época tidos como de origem orgânica.

A região do Gurupi se apresenta como uma das mais importantes $\sim$ e mais ricas regiões em variedades composicionais de lateritos, tendo grande complexidade evolutiva e met alogenética. Os fosfatos de alumínio exercem um papel muito peculiar nos lateritos em geral, como mostram os trabalhos de Costa et al (1978), Costa (1980), Costa \& Sá (1980), Costa et al (1980), Oliveira \& Schwab (1980), Costa (1982), Siqueira \& Lima (1982), Lima \& Reimão (1983), Schwab et al. (1983), Costa (1984), Schwab et al (1989) e Costa \& Araújo (1990). Na década de 80, o Centro de Geociências também se envolveu com o estudo dos grandes depósitos de bauxita, a exemplo de Paragominas, por Kotschoubey \& Truckenbrodt (1981), Truckenbrodt \& Kotschoubey (1981), Truckenbrodt (1982), Truckenbrodt et al. (1982), Kotschoubey et ai (1984); do Baixo Amazonas, por Kotschoubey (1984); de Carajás, por Lemos \& Villas (1983), Corrêa et al. (1984), Kotschoubey \& Lemos (1985), Schwab et al. (1985) e Costa et al. (1991). Kotschoubey (1988) correlacionou os depósitos de bauxitas da Amazônia com os demais do Brasil. Costa (1990a, b) descreveu o potencial mineral da Amazônia e os processos de lateritização de modo geral. 
Ao mesmo tempo, outros pesquisadores de outras instituições brasileiras e estrangeiras passaram a se interessar pêlos lateritos da região amazônica: Valarelli et al (1978), Beisiegel (1982), Bernardelli et al (1983), Alves et al (1984), Vieira é ai (1984), Groke eí al. (1985), Beauvais et al (1987), em Carajás; Aleva (1981), Chauvel eíal. (1983), Lucas (1989) e Lucas et al (1989), no Baixo Amazonas; Kronberg et al. (1979a), Kronberg et al. (1982), em Paragominas.

A experiência adquirida com o estudo dos lateritos das regiões do Gurupi, Baixo Amazonas, Paragominas e Carajás abriu perspectivas de pesquisa de lateritos na Amazônia. Tanto que, ainda na década de 80 , descobriram-se grandes depósitos de bauxita no Pitinga-AM (Costa et al. 1988), lateritos auríferos no Amapá (Veiga et al 1985) e gossans lateritizados em Carajás (Costa 1987). As investigações se estenderam a regiões distantes, como Acre e Rondônia (Costa 1985 e 1988b), Maraconaí - PA (Oliveira et al. 1988), Maicuru - PA (Lemos \& Costa 1987, Costa et al. 1990) e Seis Lagos - AM (Corrêa et al. 1988).

A partir de 1985, as companhias de mineração também passaram a se interessar pêlos lateritos, após tomarem conhecimento de sua importância para met als preciosos (ouro), patrocinando o treinamento de seus profissionais.

Diante desse quadro, este trabalho tentará organizar o conhecimento geológico sobre os lateritos da Amazônia e o seu potencial mineral, com o objetivo de dar suporte ao estudo sistemático e para estimular o debate.

CONCEITOS O termo laterito é atualmente aplicado de forma mais ampla do que nas últimas décadas. Para Schellmann (1980), laterito é o produto de intenso intemperismo de rochas subaéreas, fazendo com que os teores de $\mathrm{Fe}$ e /ou $\mathrm{Al}$ sejam mais elevados e os de Si mais baixos nos lateritos do que na rocha-mãe apenas caolinizada. Bardossy (1982) conceitua bauxitas como rochas derivadas dos processos de lateritização. Neste trabalho, o termo laterito é usado para designar rochas formadas ou em fase de formação por meio de intenso intemperismo químico de rochas preexistentes, inclusive de lateritos antigos, sob condições tropicais, ou equivalentes. Lateritos são caracteristicamente ricos em $\mathrm{Fe}$ e $\mathrm{Al}$ e pobres em $\mathrm{Si}, \mathrm{K}$ e $\mathrm{Mg}$, se comparados à composição de sua rocha-mãe. Os lateritos podem ser compactos, maciços, coesos e incoesos, terrosos ou argilosos, com coloracão variando de vermelho, violeta, amarelo, marrom até o branco. Sua composição mineralógica envolve geralmente oxi-hidróxidos de ferro (goethita e hematita), de alumínio (gibbsita e bõhmita), titânio (anatásio) e de manganês (litioforita, todorokita etc); argilo-minerais (caulinita e esmectita); fosfates (crandalita-goyazita, augelita, outros) e resistatos (turmalina, cassiterita, rutilo etc). A textura, estrutura, mineralogia, composição química e coloração das rochas lateríticas variam amplamente em seção vertical, dando origem a uma sucessão característica de horizontes suborizontais e compondo os já classicamente conhecidos perfis lateríticos.

NOMENCLATURA Existem várias propostas para a nomenclatura e classificação de lateritos (Valeton 1972, Aleva 1981). Este trabalho propõe uma adaptação à nomenclatura de Aleva \& Bardossy (apud Banerji 1982), os quais usam o termo laterito adjetivado, ou pelo elemento químico mais característico ou pelo mineral-minério ou pelo minério associado. Assim, lateritos contendo muito ferro são denominados de lateritos ferruginosos, lateritos ricos em fosfates, de lateritos fosfáticos, e aqueles ricos em hidróxidos de $\mathrm{Al}$, lateritos bauxíticos. Nesse último caso, pode ser usada também a denominação bauxitas lateríticas, quando se quer diferenciá-las das cársticas, das sedimentares etc. Caso se desejem informações sobre a rocha-mãe, acrescenta-se o termo, "derivado de" e o nome da rocha. Na Amazônia, por exemplo, ocorrem lateritos bauxíticos derivados de traquitos (Pitinga-AM), la- teritos bauxíticos ferruginosos derivados de basaltos, lateritos ba $u$ xíticos derivados de argilitos etc.

DISTRIBUIÇÃO GEOGRÁFICA Os lateritos são encontrados por toda a região Amazônica (Fig. 1). Entretanto, somente os lateritos ferruginosos e bauxíticos constituem grandes corpos. As principais regiões lateríticas identificadas na Amazônia são:

1. Gurupi (Pará-Maranhão) - grande diversidade de rochas lateríticas, predominando as fosfáticas; 2. Paragominas-Capim (Pará) - grandes depósitos de lateritos bauxíticos e caulínicos; 3. Carajás (Pará) - vários tipos de lateritos, sendo mais importantes os ferruginosos, bauxíticos, manganesíferos, auríferos e niquelíferos; 4. Baixo Amazonas (Pará) - principalmente na borda norte do Rio Amazonas: a. Trombetas, Nhamundá e Faro - lateritos bauxíticos b. Almeirim, Monte Dourado e Felipe - lateritos bauxíticos e caulínicos; 5. Pitinga (Amazonas) - grande variedade, principalmente lateritos bauxíticos e com resistatos ( $\mathrm{Sn}, \mathrm{Nb}, \mathrm{Y}$ ).

Outros depósitos pequenos, isolados, destacam-se dentro do quadro atual de conhecimento geológico da Amazônia:

6. Cassiporé (AP); 7. Vila Nova (AP); 8. Serra do Navio (AP); 9. Tucuruí (PA); 10. Quatipuru (PA); 11. Manaus (AM) e outros.

Além disso, corpos isolados, geralmente protegidos por espessos chapéus-de-ferro ressaltam-se na Amazônia: 12. Maraconaí (PA) 13. Maicuru (PA); 14. Seis Lagos (AM) (Fig. 1).

Por outro lado, plintitos (horizonte argiloso mosqueado), petroplintitos (horizonte ferruginoso concrecionário) - neste trabalho denominados de lateritos imaturos - recobrem toda a região Amazônica, exceto aquelas áreas com cobertura sedimentar pleistocênica tardia a holocênica. As exposições melhor conhecidas atualmente estão em Rondônia, no Acre, no Gurupi (Pará-Maranhão), Paragominas (PA), Pitinga (AM) e Monte Alegre (PA).

\section{GRAU DE EVOLUÇÃO E NATUREZA DOS PERFIS}

Os lateritos da Amazônia podem ser classificados em dois grandes grupos, com base em suas feições geográficas, mineralógicas e geoquímicas, os quais estão relacionados com o grau de evolução:

Lateritos imaturos Estão distribuídos por toda região, e formam o relevo jovem que domina em toda Amazônia. Os perfis de tais lateritos apresentam características típicas de baixo grau de evolução. A presença de um horizonte concrecionário ferruginoso é clássico.

Lateritos maturos Estão muito bem representados na Amazônia, mas não têm a mesma extensão geográfica dos imaturos, restringindo-se às regiões específicas descritas anteriormente e indicadas na figura 1. Em geral, compõem o relevo mais elevado, sob a forma de platôs ou morros. São lateritos evoluídos, com maior complexidade de horizontes, texturas, estruturas, mineralogia, feições geoquímicas e mineralizações associadas. Esses lateritos mostram em geral feições típicas de processos policíclicos (Kotschoubey \& Truckenbrodt 1981) e epigenéticos (Costa 1990a, c).

\section{Natureza dos perfis lateríticos da Amazônia Da} mesma forma que qualquer laterito de outras regiões ou províncias, podem ser classificados também em: autóctones elou alóctones. Lateritos maturos e imaturos podem ocorrer tanto na forma autóctone como alóctone.

A identificação da natureza autóctone ou alóctone é feita com base na sucessão dos horizontes e nas respectivas texturas e estruturas.

Os lateritos alóctones, conhecidos também na região por linhas de pedra e paleopavimentos, parecem ser mais rés- 


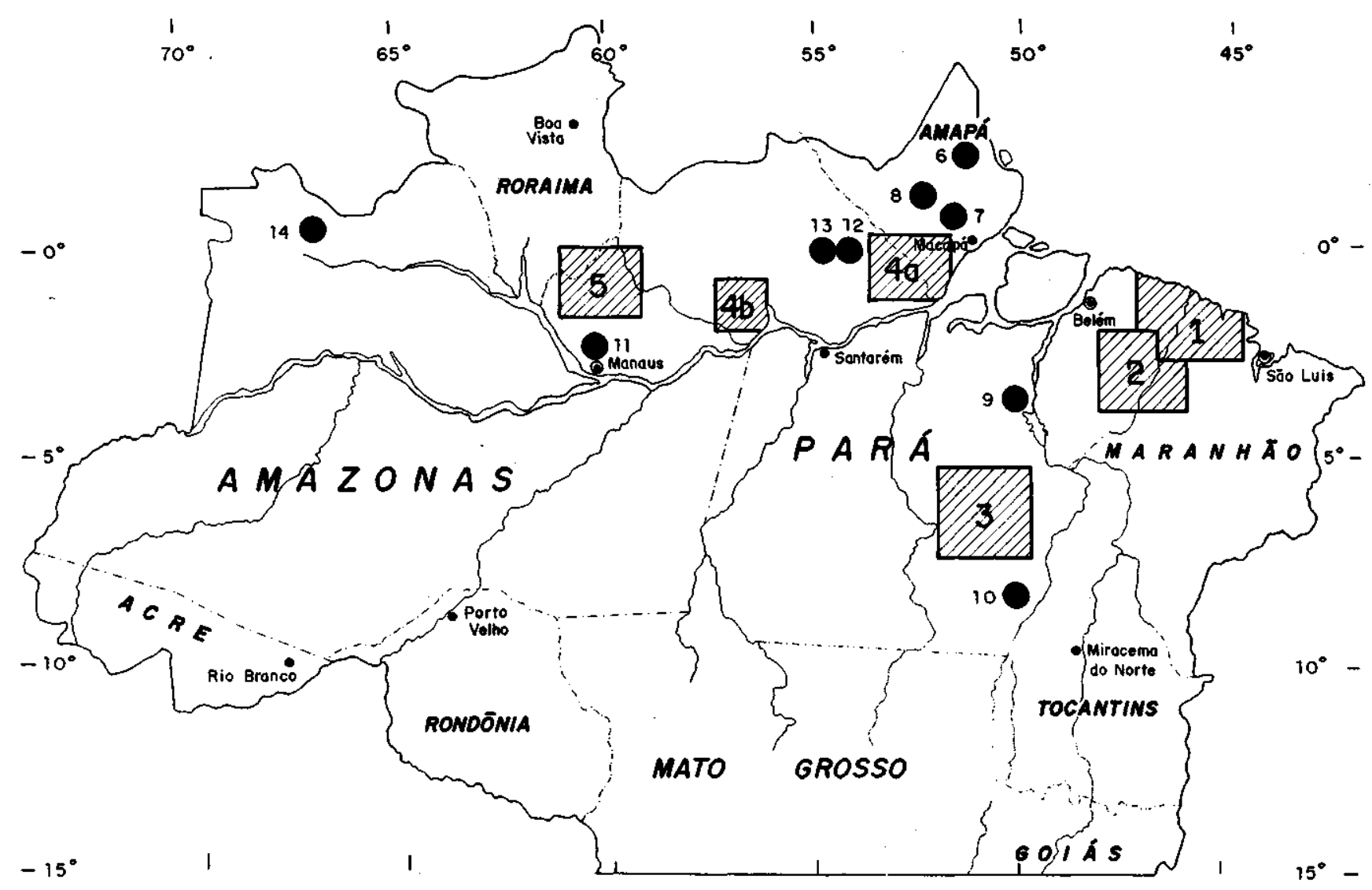

Figura 1 - Distribuição geográfica das principais regiões e corpos isolados lateríticos conhecidos na Amazônia Figure l - Geographical distribution of main known laterite regions and isolated bodies in Amazônia

tritos do que os autóctones. A observação mostra que os alóctones, em geral, são constituídos de lateritos imaturos.

LATERITOS IMATUROS AUTÓCTONES Os perfis lateríticos imaturos autóctones apresentam três horizontes característicos (Fig. 2):

Horizonte ferruginoso (petroplintito) Ocorre na porção superior do perfil e exibe uma ou mais das seguintes características:

- nódulos, concreções, esferólitos e fragmentos compostos de oxi-hidróxidos de ferro em matriz argilosa a terrosa;

- uma crosta composta pêlos elementos acima, cimentados por filmes microcristalinos ou por cimento (plasma) microcristalino gibbsito-caulinítico.

- uma crosta formada de oxi-hidróxidos de ferro entrelaçando porções argilosas amareladas.

A cor dominante do horizonte ferruginoso é a marromavermelhada, onde a matriz/cimento, se presente, é brancaamarelada ou cinza.

Nódulos, concreções, esferólitos e plasmas (micro a criptocristalino) são as estruturas dominantes, seguidas por colunas, canais em forma de raízes e vermes, entre outras, e aquelas resultantes de lixiviação, como as cavernosas, esponjosas e porosas. Córtex formados por oxi-hidróxidos de ferro e alumínio são também muito abundantes. Eles são multicoloridos, envolvendo alternância de bandas marromescuras e claras.

Estruturas reliquiares são raras, encontradas apenas no núcleo dos esferólitos.

Horizonte argiloso Ocorre logo abaixo do ferruginoso (Fig. 2), em contato quase abrupto. E constituído fundamen-

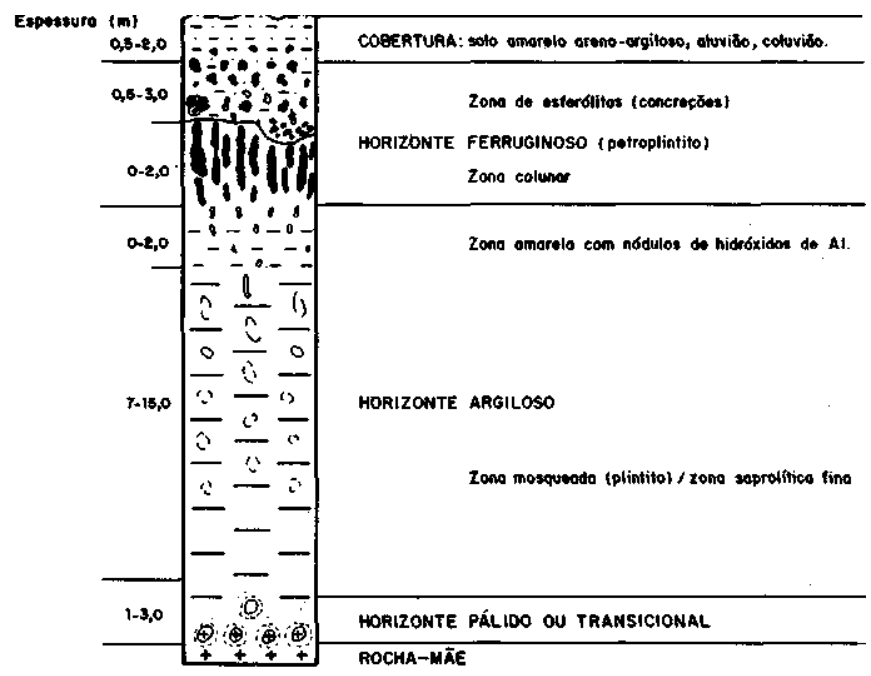

Figura 2 - Perfil geológico simplificado de lateritos imaturos autóctones na Amazônia

Figure 2 - Simplified geological profile of autochthone immature laterites of the Amazon region

talmente de argilominerais e exibe as seguintes feições, estritamente relacionadas com a natureza da rocha-mãe:

Zona mosqueada/amarelada (plintito): esta é a feição mais característica do horizonte argiloso, quando derivado de rochas ígneas ácidas e intermediárias e de sedimentares. Trata-se de um horizonte de arguas intempéricas, manchadas 
irregularmente de vermelho e violeta por dispersão de micropartículas de óxi-hidróxidos de ferro, que se instalam nos planos de clivagem e fratura.

$\mathrm{Na}$ parte superior do horizonte argiloso, as manchas se transformam em nódulos ou colunas, ou mesmo desaparecem, originando uma zona nodular amarela a marrom.

Zona saprolítica: é um termo empregado para descrever o intemperismo de rochas cristalinas no estágio de argilominerais no qual fragmentos da rocha parcialmente alterada, desde escala milimétrica no topo (saprólito fino) a centimétrica na base (saprólito grosso); são ainda encontrados dentro de plasma argiloso. O saprólito originado de rochas félsicas e intermediárias e de sedimentares é quase sempre do tipo mosqueado na sua porção mediana e superior. Por outro lado, aquele derivado de rochas máficas e ultramáficas, xistos e filitos, dificilmente se deixa mosquear.

No horizonte argiloso, texturas e estruturas reliquiares são abundantes e in situ. Estruturas neoformadas estão representadas por manchas marrom-avermelhadas, colunares ou irregulares, por nódulos discretos, pêlos córtex ao longo de superfície de veios, fraturas, ou por auréolas de difusão multicoloridas e concêntricas em torno dos fragmentos de rochas em vias de intemperismo. A espessura, que depende da natureza da rocha-mãe e da região, varia de 7 a $15 \mathrm{~m}$ sobre rochas sedimentares, ígneas félsicas e máficas, e pode ser muito espessa sobre rochas ultramáficas e metamórficas de foliação subvertical.

Horizonte pálido ou transicional Encontra-se imediatamente abaixo do horizonte argiloso, em contato direto com a rocha-mãe, numa espécie de base de saprólito. Caracteriza-se pela coloração mais pálida relativa à cor da rochamãe, em decorrência da decomposição dos minerais máficos, dos sulfetos e da matéria orgânica, sem que ainda tenha havido a formação de óxi-hidróxidos de ferro. Este horizonte é formado basicamente de argilominerais complexos, em convivência desequilibrada com minerais primários instáveis ao intemperismo. O horizonte representa assim o estágio transicional entre a rocha-mãe e o horizonte argiloso. Caracteriza-se ainda por grande abundância de fragmentos da rocha-mãe envoltos por pálidas auréolas de intemperismo, em restrita matriz terrosa e argilosa. A maioria das estruturas primárias estão preservadas.
Mineralogia As espécies minerais dos lateritos imaturos da Amazônia estão apresentadas na tabela 1. As mais importantes são:

- Hematita, goethita, goethita com alumínio e maghemita.

- Caulinita, halloysita, esmectita e illita.

O primeiro grupo é típico do horizonte ferruginoso, enquanto o segundo, junto com o primeiro, representam o horizonte argiloso, sendo que esmectita e illita são mais características do horizonte pálido. Hematita, maghemita e goethita compõem os nódulos, núcleos dos esferólitos e estruturas colunares, e goethita com alumínio, os córtex no horizonte ferruginoso. Goethita com alumínio constitui também veios e preenchimento de fraturas do horizonte argiloso. Outros minerais apresentam-se em teores discretos: anatásio criptocristalino, e hidróxidos de Mn como películas negras nas superfícies de clivagem e de fratura. Ouro singenético encontra-se especialmente na zona de contato entre os horizontes ferruginoso e argiloso.

Mais det alhes sobre a mineralogia dos lateritos imaturos encontram-se em Kronberg et al. (1979b), Sombroek \& Camargo (1983), Costa (1985) e Costa et al (1988a, b).

Composição química A composição química dos lateritos imaturos ainda é pouco conhecida. Os dados disponíveis (Kronberg et al 1979b, Costa 1985, 1988a, b) mostram que os teores de $\mathrm{SIO}_{2}, \mathrm{MgO}$ e $\mathrm{K}_{2} \mathrm{O}$ decrescem da rocha-mãe para o horizonte ferruginoso, enquanto $\mathrm{Fe} 2 \mathrm{C}>3, \mathrm{AbOa}$ e TiÜ2 aumentam nesse sentido. Esse padrão químico corrobora a mineralogia anteriormente descrita. Para os elementos traços, ainda não é possível apresentar um modelo, devido à ausência de dados significativos. $\mathrm{O}$ único trabalho que contém análises mais representativas (46 elementos) é o de Kronberg et al. (1979b), para perfil incompleto.

Os núcleos dos esferólitos, das concreções e dos nódulos do horizonte ferruginoso têm maior significado geoquímico porque são capazes de discriminar a natureza das rochas-mães e mineralizações associadas, tanto para os elementos pouco móveis $(\mathrm{Cr}, \mathrm{Ti}, \mathrm{Sn})$, como para os relativamente móveis $(\mathrm{Cu}$, $\mathrm{Ni}, \mathrm{Co}$ ). A dispersão desses elementos no horizonte argiloso é relativamente menor do que no ferruginoso. Por outro lado, elementos de alta mobilidade, cujo comportamento depende do potencial de oxi-redução, como ouro, elementos do grupo da platina (EGP), urânio etc, podem se concentrar nos córtex e nos plasmas ferruginosos.

Tabela 1 - Os minerais mais frequentes dos lateritos imaturos da Amazônia Table 1 - The most frequent minerais of immature laterites of Amazon regions

\begin{tabular}{l|l}
\hline HORIZONTES & ESPÉCIES E/OU GRUPOS MINERAIS \\
\hline COBERTURA/SOLO & CAULINITA, QUARTZO, GOETHITA ALUMINOSA, HEMATITA. \\
\hline \multirow{5}{*}{ FERRUGINOSO } & $\begin{array}{l}\text { Concreções esferoidais e colunares: } \\
\text { HEMATITA, GOETHITA, GOETHITA ALUMINOSA, maghemita, quartzo, caulinita } \\
\text { gibbsita, anatásio, ouro. } \\
\text { Matriz de aspecto areno-argiloso: } \\
\text { CAULINITA, QUARTZO, GOETHITA ALUMINOSA, GOETHITA, gibbsita, anatásio. }\end{array}$ \\
& $\begin{array}{l}\text { Zona nodular amarela: } \\
\text { CAULINITA, QUARTZ, gibbsita, goethita. }\end{array}$ \\
& $\begin{array}{l}\text { Zona mosqueada/saprolítica: } \\
\text { CAULINITA, HALLOYSITA, QUARTZO, HEMATITA, GOETHITA, esmectita, illita, } \\
\text { oxi-hidróxidos de Mn. }\end{array}$ \\
\hline PÁLIDO OU TRANSICIONAL & ESMECTITA, ILLITA, MINERAIS PRIMÁRIOS.
\end{tabular}


Modo de ocorrência Os lateritos imaturos da Amazónia ocorrem nas seguintes formas:

- relevo recente, quase plano, desenvolvido sobre crostas ferruginosas ou concreções ferruginosas incoesas, representando a exposição do horizonte ferruginoso.

- relevo quase plano a ondulado, instalado sobre latossolos autóctones e alóctones originados de lateritos imaturos onde se desenvolveu uma floresta tropical exuberante e densa.

Localmente, estas superfícies já estão dissecadas suficientemente, em consequência do rebaixamento do nível de base (soerguimento tectônico), originando diversos platôs. É também comum a exposição direta do horizonte argiloso (mosqueado, saprolítico), que favorece um relevo mais ondulado e sobre o qual se instalaram latossolos.

LATERITOS MATUROS AUTÓCTONES Os lateritos maturos ou evoluídos da Amazônia, ao contrário dos imaturos, apresentam-se em perfis mais desenvolvidos, com grande variedade de texturas e estruturas singenéticas, e amplo espectro de espécies minerais. Os perfis são sempre compostos dos seguintes horizontes (Figs. 3 a 5): crosta ferruginosa, horizonte bauxítico e/ou de fosfatos de alumínio, horizonte argiloso e o pálido ou transicional.

Crosta ferruginosa Encontra-se normalmente no topo dos perfis, em geral sob a forma de rocha dura e densa, muitas vezes magnética, de coloração marrom-avermelhada. $\mathrm{O}$ seu arcabouço geral tem os seguintes aspectos:

- agregados de nódulos, concreções e esferólitos vermelhos de oxi-hidróxidos de ferro, cimentados por fosfatos e/ou hidróxidos de alumínio, brancos e amarelos, originando um material tipo conglomerado, similar a pele de onça; fragmentos e pseudofragmentos de material ferruginoso (como oxihidróxidos) com cimento igual ao anterior, descrevendo um material brechóide;
- fragmentos marrom-avermelhados, também de oxi-hidróxidos de ferro, ligados entre si apenas por meio de finos córtex microcristalinos, criando um padrão pisolítco;

- ou por entrelaçamento irregular de material rico em oxi-hidróxidos de ferro, que envolve um outro padrão equivalente ao cimento dos casos anteriores. Este padrão representa o endurecimento e a recristalização do padrão mosqueado do horizonte argiloso.

Estruturas primárias reliquiares são raras e deslocadas.

O proto-horizonte das crostas ferruginosas é, dessa forma, tanto o horizonte ferruginoso como o mosqueado dos lateritos imaturos.

Na Amazônia, a crosta ferruginosa, por se encontrar próxima à superfície, está atualmente em via de intemperismo e assim recoberta também por latossolos areno-argilosos autóctones e alóctones. Excepcionalmente, como no Gurupi, Carajás, Maicuru, Maraconaí e em outras regiões da Amazônia, a crosta está desnuda, formando o relevo.

\section{Horizonte bauxítico e/ou de fosfatos de alumínio}

Encontra-se geralmente logo abaixo do crosta ferruginosa, em contato direto e quase abrupto. É constituído de uma rocha amarela, de creme a vermelha, formada de blocos centimétricos a métricos, nódulos e esferólitos, numa matriz argiloarenosa de abundância variável. Localmente, forma uma camada dura (crosta aluminosa) de continuidade lateral. Sua constituição mineralógica é basicamente formada de hidróxidos (bauxita) e/ou de fosfatos de alumínio.

Estruturas reliquiares não são raras, mas estão deslocadas. As mais comuns são pseudomorfos de fenocristais, de blasteses, de vênulas, de porfiroblastos, de moldes de raízes e de bioturbações. São comuns as estruturas singenéticas, como esferólitos (oólitos, pisólitos etc.). Também são frequentes os aspectos cavernosos e esponjosos, estruturas colunares e laminares suborizontais.

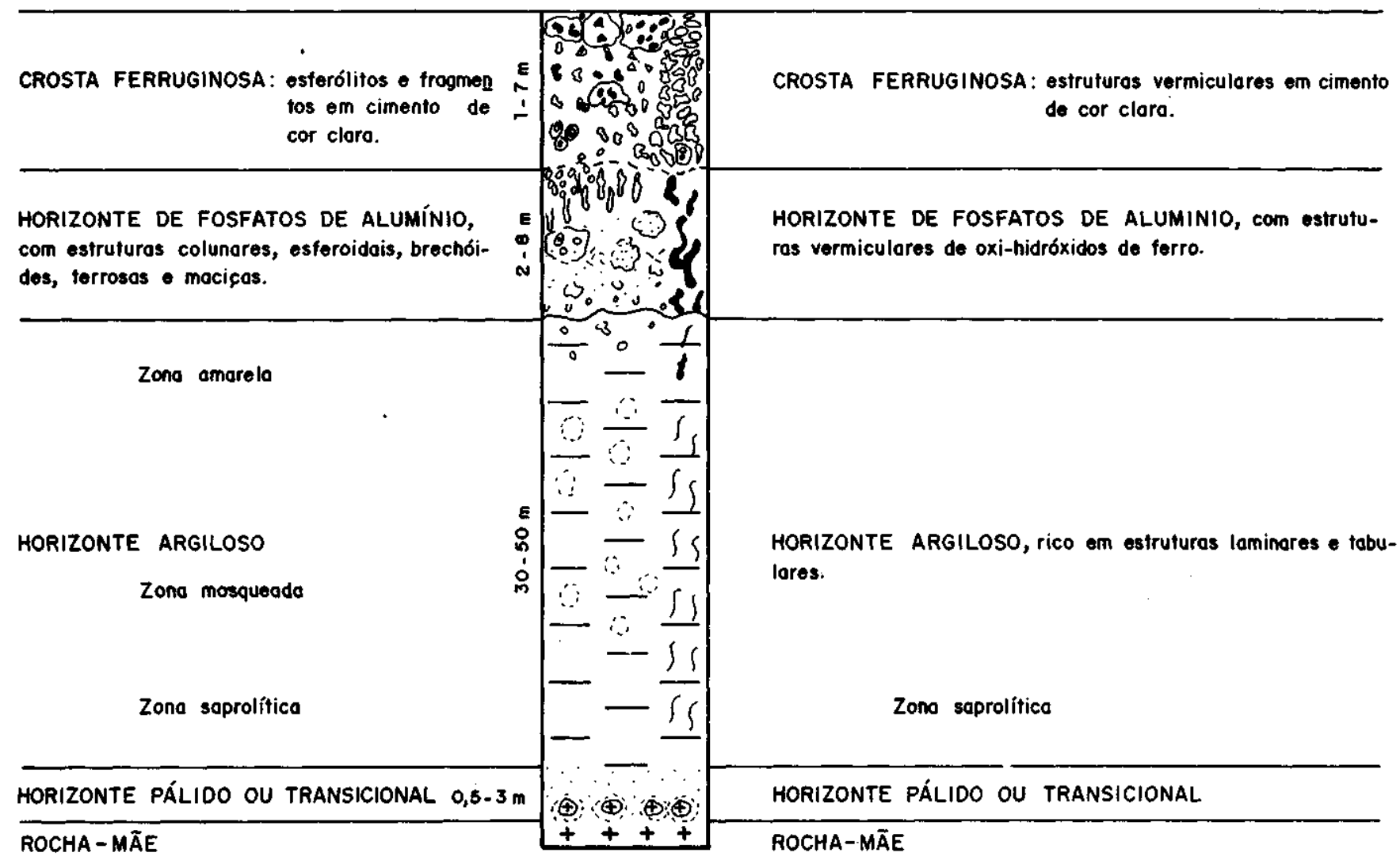

Figura 3 - Perfil geológico simplificado de lateritos fosfáticos maturos autóctones na Amazônia

Figure 3 - Simplified geological profile of autochthone mature phosphatic laterites of the Amazon region 


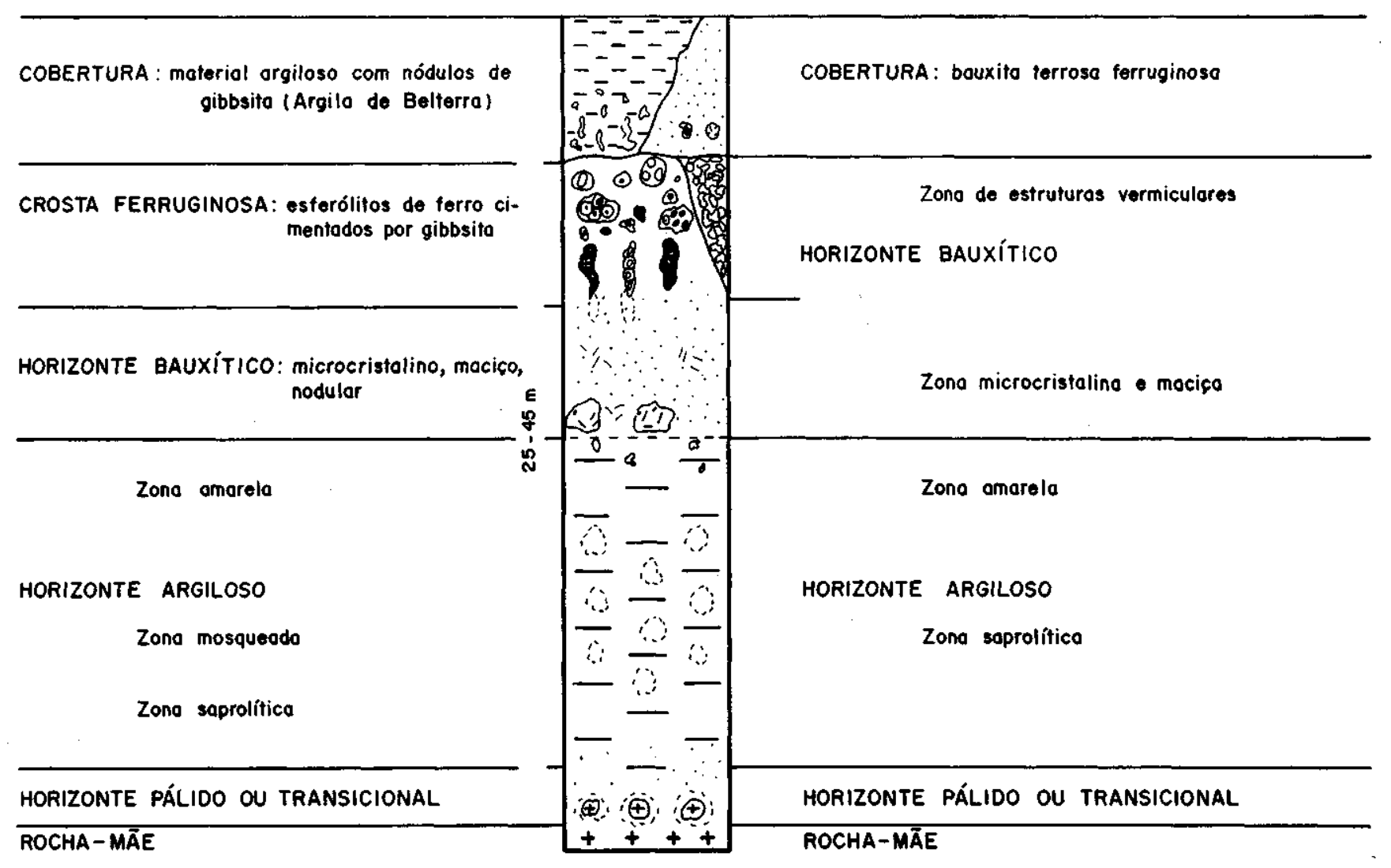

Figura 4 - Perfil geológico simplificado de lateritos bauxíticos maturos autóctones na Amazônia (exemplo, Tiracambu, Pitinga, Paragominas)

Figure 4 - Simplified geological profile of autochthone mature bauxitic laterites of the Amazon region (Ex.: Tiracambu, Pitinga, Paragominas)

O horizonte bauxítico e/ou fosfático é o melhor critério para distinguir lateritos maturos dos imaturos, o qual está ausente nestes últimos. Lateritos maturos, derivados de rocha ultramáfica, por outro lado, não apresentam um horizonte bauxítico e/ou fosfático típico: entretanto, seus aspectos gerais são reconhecíveis localmente (Fig. 5).

Este horizonte comporta as maiores reservas de bauxita (Paragominas, Baixo Amazonas, Carajás, Pitinga) e de fosfates de Al (Gurupi, Maicuru) da Amazônia. Se exposto à superfície, é facilmente intemperizado, transformando-se em material argiloso, tipo Argila de Belterra (Fig. 4). Eventos policíclicos e/ou fatores litológicos deram origem, em muitos corpos lateríticos, a relações complexas entre o horizonte bauxítico e/ou fosfático e a crosta ferruginosa.

Horizonte argiloso Encontra-se logo abaixo do horizonte bauxítico e/ou fosfático, em contato quase abrupto. Nele, os minerais singenéticos mais representativos são os argilo-minerais e os oxi-hidróxidos de ferro.

Esse horizonte pode apresentar as seguintes zonas: a mosqueada, o saprólito mosqueado, o saprólito marrom e a zona argilosa e/ou terrosa de amarela a marrom (Figs. 3 a 5). A parte superior deste horizonte é rica em estruturas singenéticas, enquanto a parte inferior contém muitas estruturas reliquiares. A espessura do horizonte varia de $10 \mathrm{a} 30 \mathrm{~m}$, podendo ser muito superior, se tiver sido derivada de rochas metamórficas foliadas, ou de ultramáficas e carbonatíticas.

Horizonte pálido ou transicional Corresponde à transição entre a rocha-mãe na base e o horizonte argiloso acima. Tem as mesmas características do seu equivalente nos perfis imaturos.
Mineralogia Lateritos maturos, quando comparados com os imaturos, apresentam um espectro maior de espécies minerais. A distribuição deles ao longo do perfil é também controlada por cada horizonte. Os minerais de neoformação mais característicos estão indicados na tabela 2 , onde se destacam as seguintes classes:

- Elementos nativos: ouro.

- Oxi-hidróxidos de Fe, Al, Mn e Ti: hematita, goethita, goethita com alumínio, maghemita, gibbsita, boehmita, lithioforita, todoroquita, birnessita, anatásio e outros.

- Fosfates de Al, Al-Ca-Sr-ETR, Al-Ca-Na, Ca-Fe-Mg e Fe: crandallita-goyazita-florencita, wardita, dufrenita, mitridadatita etc.

- Filossilicatos (argilominerais): caulinita, esmectita, illita.

- Resistatos: zircão, turmalina, cassiterita, rutilo, ilmenita, estaurolita, cianita, etc.

Os oxi-hidróxidos de ferro são típicos da crosta ferruginosa, formando os nódulos, as concreções, os esferólitos e os fragmentos. Também são encontrados em outros horizontes, embora em menor quantidade, como nódulos, massas irregulares, manchas e vênulas. A maghemita é a responsável pela natureza ferromagnética de crostas de várias regiões. Os fosfates de ferro são aparentemente típicos das crostas, formando nódulos e manchas, provavelmente de origem epigenética (Costa 1991).

Gibbsita, boehmita, grupo da crandallita, augelita, variscita, wardita e senegalita são os minerais típicos do horizonte bauxítico e/ou fosfático. Esses minerais também são encontrados em menor quantidade na crosta ferruginosa, onde se restringem ao cimento e/ou à matriz e às vênulas. Eles também podem constituir nódulos, esferólitos e colunas; os fosfatos ainda formam esferólitos e nódulos fibrorradiais. 


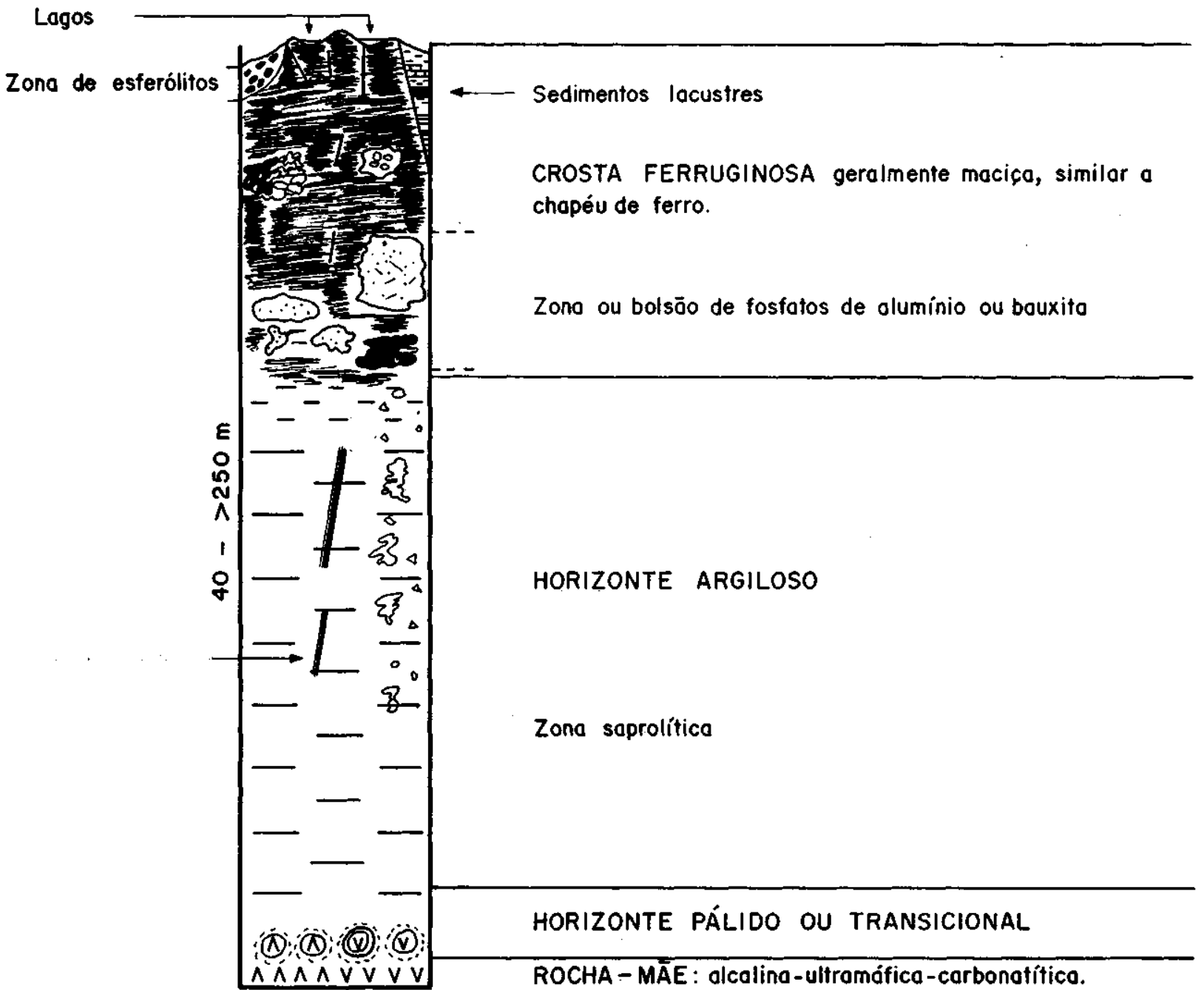

figura 5 - Perfil geológico simplificado de lateritos jnaturos com estruturação tipo chapéu-de-ferro na Amazônia (exemplo, Maicuru e Maraconaí, no Pará, Seis Lagoas, no Amazonas)

Figure 5 - Simplified geological profile of autochthone mature laterites with iron hat structuration on Amazon region (Ex.: Maicuru - PA, Maraconaí - PA, Seis Lagos - AM)

Caulinita e halloysita constituem o horizonte argiloso (mosqueado, saprolítico), enquanto os minerais do grupo da esmectita são mais comuns no horizonte pálido ou transicional. Os argilominerais constituem o arcabouço fundamental desses dois horizontes, sendo comumente mosqueados e atravessados por vênulas de hematita e goethita.

Hidróxidos de Mn como litioforita, todorokita e birnessita podem formar localmente grandes concentrações, até de minérios, como no Azul (Carajás) e Serra do Navio (Amapá).

Goethita com (Ni, Co, Cu, Cr) e esmectita com (Ni, Co, $\mathrm{Cu}, \mathrm{Pb}, \mathrm{Zn}, \mathrm{Sr}, \mathrm{Ba}$ ), encontram-se no horizonte pálido e argiloso, derivadas de rochas máfico-ultramáficas.

O ouro ocorre como grãos (pepitas) de tamanho variado, em geral pequenos, disseminados nos horizontes superiores. Fato interessante é o de que, o ouro, mesmo em concentrações relativamente baixas, na faixa de ppb a ppm, inferiores à maioria dos elementos traços em lateritos, forma seu mineral próprio, o ouro, enquanto os demais elementos não.

Nos lateritos maturos são encontrados os mesmos minerais resistatos dos imaturos, que se concentram nos horizontes superiores. No Pitinga (AM), cassiterita, columbita, xenotima e zircao estão concentrados no perfil laterítico com potencial económico.

Composição química A composição química dos lateritos maturos da Amazônia é extremamente variável e com- plexa devido à diversidade químico-mineralógica e às mineralizações das respectivas rochas-mães, bem como aos efeitos policíclicos e epigenéticos a que foram submetidos posteriormente esses lateritos. Desta forma, é ainda quase impossível estabelecer composição química média para os lateritos maturos da região.

Talvez seja mais significativo mostrar as relações gerais entre a concentração dos elementos principais nos horizontes e na respectiva rocha-mãe. Com base nesse procedimento, os lateritos maturos apresentam da base (rocha-mãe) para o topo dos perfis, os seguintes aspectos geoquímicos:

- $\mathrm{SiU} 2, \mathrm{KaO}, \mathrm{MgO}$ e $\mathrm{MnO} 2$. seus teores decrescem abruptamente. SiÜ2 e KjO o fazem na interface do horizonte argiloso para o bauxítico-fosfático,

- $\mathrm{Fe}_{2} \mathrm{O} 3, \mathrm{TiO} 2, \mathrm{Al}_{2} \mathrm{O}_{3}$ e $\mathrm{H}_{2} \mathrm{O}$ : seus teores crescem gradualmente para o topo; $\mathrm{FezCb}$, como já citado, experimenta aumentos bruscos na crosta.

Esses são os padrões gerais dos lateritos maturos e mesmo dos imaturos. $\mathrm{CaO}, \mathrm{Na}_{2} \mathrm{O}$ e $\mathrm{P}_{2} \mathrm{O}_{5}$, cujos teores normalmente decrescem para o topo do perfil, podem, nessa direção, até mesmo aumentarem quando há formação de fosfatos de alumínio, o que é menos comum do que os hidróxidos de alumínio.

Os elementos traços apresentam-se também em um dos padrões de distribuição dos elementos principais, que constituem a mineralogia essencial dos perfis: 
Tabela 2 - Os minerais mais frequentes dos lateritos maturos da Amazônia Tabela 2 - The most frequent minerais of matute laterites of Amazon region

\begin{tabular}{|c|c|}
\hline HORIZONTES & ESPÉCIES E/OU GRUPOS MINERAIS \\
\hline \multirow{6}{*}{ COBERTURA/SOLO } & Argila de Belterra/solo: \\
\hline & CAOLINITA, QUARTZO, GOETHITA ALUMINOSA, gibbsita. \\
\hline & Litorrelictos, nódulos: \\
\hline & GIBBSITA, CAULINITA, QUARTZO, hematita, goethita. \\
\hline & Sedimentos: \\
\hline & SIDERITA, PIRITA, turfa, fosfatos de ferro. \\
\hline \multirow{6}{*}{ CROSTA FERRUGINOSA } & Nódulos, esferólitos e fragmentos de cor vermelha: \\
\hline & HEMATITA, GOETHITA, quartzo, caulinita, anatásio, gibbsita, fosfatos de alumínio, ouro. \\
\hline & Córtex: \\
\hline & Goethita aluminosa, gibbsita. \\
\hline & Cimento/matriz de cor clara: \\
\hline & GIBBSITA, FOSFATO DE ALUMÍNIO, anatásio, quartzo, goethita. \\
\hline BAUXITICO E/OU & GIBBSITA, Gr. da CRANDALLITA, AUGELITA, VARISCITA, WARDITA, \\
\hline Al-FOSFÄTICO & SENEGALITA, hematita, goethita, anatásio, quartzo, caulinita, ouro. \\
\hline \multirow{5}{*}{ ARGILOSO } & Nódulos amarelos: \\
\hline & CAULINITA, GIBBSITA, Gr. da CRANDALLITA, VARISCITA, WARDITA. \\
\hline & \\
\hline & Zona mosqueada/saprolítica \\
\hline & $\begin{array}{l}\text { CAULINITA, QUARTZO, HALLOYSITA, HEMATITA, GOETHITA, goethita } \\
\text { com alumínio, esmectita, illita, oxi-hidróxidos de } \mathrm{Mn} \text {. }\end{array}$ \\
\hline PÁLIDO OU TRANSICIONAL & ESMECTITA, ILLITA, MINERAIS PRIMÁRIOS. \\
\hline
\end{tabular}

- V, Cr, Ga, e Mo: seus teores aumentam para o topo, paralelamente ao de $\mathrm{Fe}_{2} \mathrm{O}_{3}$ e $\mathrm{Al}_{2} \mathrm{O}_{3}$, na forma de hematita, goethita e goethita rica em alumínio.

- Zr, Y, Sc, Nb, Ta, Sn e ETR: concentram-se geralmente, sob a forma de resistatos, acessórios na rocha-mãe e nos lateritos.

- Zr, Y, Sc, Nb, ETR, Ba, Rb, Pb e V: podem experimentar elevados fatores de concentração no topo do perfil, nas proporções do P2Ü5, como fosfates de alumínio (grupo da crandalita).

- $\mathrm{Ni}, \mathrm{Cu}, \mathrm{Co}, \mathrm{Mn}$ e $\mathrm{Zn}$ : seus teores aumentam apenas até o horizonte pálido e à base do argiloso, na ordem de uma a três vezes a rocha-mãe, alojando-se na estrutura dos argilominerais complexos (esmectita, vermiculita) e nos oxi-hidróxidos de ferro e de manganês.

- Ba, Rb, Sr, Pb, ETR e U: na ausência de fosfates de alumínio, apresentam o mesmo comportamento do grupo anterior e são absorvidos pêlos argilominerais complexos.

Modo de ocorrência $\mathrm{Na}$ Amazônia, os lateritos maturos ocorrem da seguinte maneira:

- platôs ou morros, cujos topos representam superfícies lateríticas reliquiares; platôs isolados atingem até $40 \mathrm{~km}^{2}$ de área, formando-se sobre lateritos bauxíticos;

- como parte do relevo recente, sem qualquer distinção morfológica devido a movimentos tectônicos em blocos, nivelando o relevo antigo com o recente, ou até mesmo invertendo-os.

LATERITOS ALÓCTONES: LINHAS DE PEDRA

As linhas de pedra são corpos lenticulares, constituídos de fragmentos de lateritos em matriz argilo-arenosa e espalhados por toda Amazônia. Estão intimamente relacionadas com a dissecação do relevo regional durante o Terciário e o Quaternário. As linhas de pedra encontram-se comumente como camadas de forma côncava ou convexa, de dezenas a centenas de metros de extenção e com espessura de centimétrica a métrica. Internamente, as linha de pedra apresentam granulocrescência (Figs. 6a e 6b). O diâmetro dos grânulos oscila entre unidades de milímetro a de centímetro, tem formas irregulares, por vezes com superfície polida, com córtex externo marrom ou amarelo. Os fragmentos mais comuns são derivados dos lateritos imaturos (horizonte ferruginoso), sobre os quais geralmente se assentam. A matriz, quando presente, é de amarela a marrom, argilo-arenosa, proveniente de latossolos e do horizonte mosqueado. Fragmentos e seixos de quartzo e de lateritos maturos (bauxita e fosfates) são também encontrados.

As linhas de pedra se encontram frequentemente em corpos argilosos ou recobertos por este material, o que lembra a Argila de Belterra.

A morfologia dos corpos das linhas de pedra sugere que elas representam paleosuperfícies, ligeiramente onduladas, desenvolvidas durante cobertura veget al tipo savana. Nas áreas amazônicas atualmente desmaiadas ou onde há ainda núcleos de savanas (Monte Alegre, Santarém), é possível observar a instalação de futuras linhas de pedra.

As linhas de pedra são, assim, resultantes da erosão de corpos lateríticos - comuns e aflorantes à época de formação delas - submetidos inicialmente ao intemperismo químico e seguido de erosão. A deposição dos fragmentos ocorre junto à área-fonte, na forma de avalanches, escorregamentos, erosão diferencial (eluviação) e transporte aquoso. 


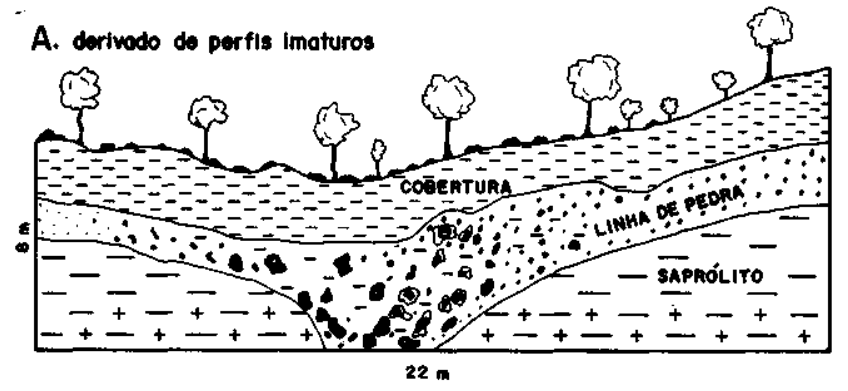

B. derivodo de pertis maturos
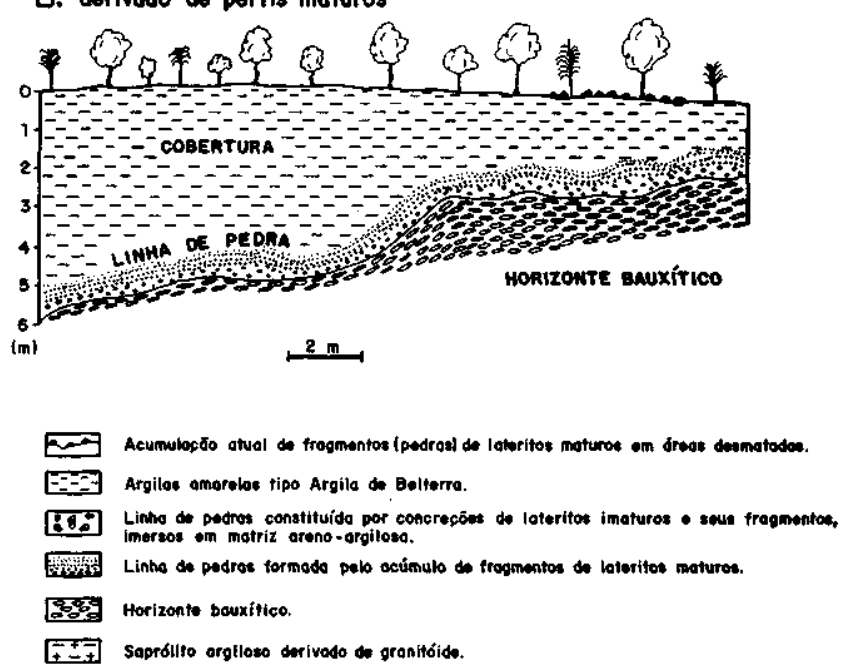

Figura 6 - Cobertura tipo Argila de Belterra e linhas-de-pedras em perfis lateríticos na Amazônia (exemplo, Pitinga-AM) Figura 6 - Belterra Clay like covers and stone lines in lateritic profiles from (Pitinga - AM)

Alguns depósitos de "piçarras" na Amazônia (piçarra é o termo que os construtores de estradas na Amazônia dão ao material terroso, rico em concentrações, nódulos e esferólitos de oxi-hidróxidos de ferro, situado na superfície do terreno ou até $2 \mathrm{~m}$ de profundidade, e empregado na construção de estradas), usados na construção civil, equivalem às linhas de pedra; outros são de fato o próprio horizonte concrecionário dos lateritos imaturos.

\section{P§EUDOLATERITOS (ROCHAS FERRUGINOSAS NAOO LATERÍTICAS: GRÉS DO PARÁ) Formações}

ferruginosas de natureza não-laterítica são muito frequentes na Amazônia. São compostas essencialmente de oxi-hidróxidos de ferro e alumínio (hematita e goethita), formando camadas, pseudoveios e bolsões isolados, sem apresentar as características dos perfis lateríticos descritos anteriormente.

Embora não sejam de origem laterítica, estas formações podem ser encontradas dentro dos próprios perfis lateríticos. Rochas ferruginosas (ironstones) não-lateríticas são encontradas no mundo inteiro. Na Amazônia, foi Katzer (1903) quem as descreveu pela primeira vez, denominando-as de Grés do Pará ou Pedra do Pará. O próprio Katzer (1903) comenta que o termo é impróprio, porque ele encontrou estas rochas ferruginosas em várias partes da Amazônia, além do Pará. O termo Grés do Pará, entretanto, ainda persiste, embora restrito ao Pará. Refere-se, geralmente, a um material areno-conglomerático quartzoso, cimentado epigeneticamente por oxi-hidróxidos de ferro. É conhecido também por pedra jacaré e piçarra, e tem amplo emprego na construção civil da região.

As rochas ferruginosas não-lateríticas, tipo Grés do Pará, são normalmente compostas de grânulos de quartzo na faixa de silte a seixos, em cimento marrom epigenético de goethita e hematita. Essa rocha é, conseqüentemente, densa e escura, representando siltitos, arenitos, conglomerados, brechas, brechas de falhas, vênulas etc, ferruginizados. Neste trabalho, as rochas ferruginosas tipo Grés do Pará são classificadas segundo o seu modo de ocorrência e origem (Fig. 7) em:

\section{Rocha ferruginosa (Grés do Pará) de interface}

É comumente encontrada como lentes na faixa de contato entre camadas arenosas e argilosas, onde há uma abrupta descontinuidade da permoporosidade, a qual se encontrava em zona aquosa oxidante (geralmente o lençol freático), rica em complexos de ferro solúveis. Pode ser encontrada junto à superficie, bem como a dezenas de metros de profundidade (Fig. 7).

Rocha ferruginosa (Grés do Pará) estratigráfica Essa se forma pela oxidação direta de camadas de siltitos, conglomerados ou mesmo argilitos, ricos em pirita e matéria orgânica, frequentes nas unidades estratigráficas terciárias e quaternárias da Amazônia, quando em contato com as águas superficiais oxidantes, à superfície ou a alguns metros de profundidade. Tanto nesse tipo de Grés do Pará como no anterior, a sequência argilosa junto ao contato com o Grés do Pará também é transformada parcialmente em goethita com alumínio, tornando-se amarela-ocre e compacta. $\mathrm{O}$ conjunto é uma rocha densa, de marrom a ocre, formando lajeados de centenas de metros de extensão e espessura comumente inferior a $20 \mathrm{~cm}$. Apedra de ferro estratigráfica pode atingir metros de espessura (Fig. 7).

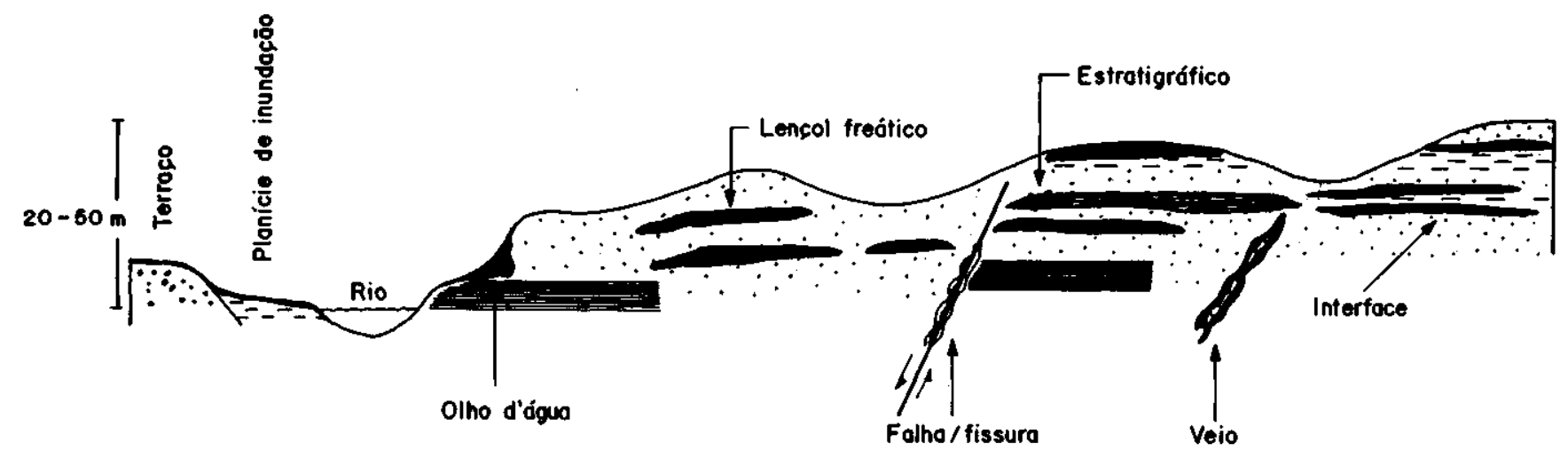


Rocha ferruginosa (Grés do Pará) de olho d'água

Esta é encontrada nos barrancos de rios e em falésias marinhas, dentro de estratos sedimentares, arenosos finos a grossos, que estiveram sob os efeitos do lençol freático, interceptados pêlos barrancos das falésias. Elas não tem representatividade areal, não são penetrativas nas encostas (Fig. 7). O Rio Madeira, em Rondônia, possui excelentes exposições destas pedras nos barrancos às suas margens.

\section{Rocha ferruginosa (Grés do Pará) de lençol freático}

É uma rocha ferruginosa comum, formada na zona de oscilação do lençol freático, independente da natureza da rocha ferruginizada, mas tão somente da sua permeabilidade. Pode ser uma parte do perfil laterítico, sendo constituída em geral por grãos de quartzo agregados por oxi-hidróxidos de ferro.

Rocha ferruginosa (Grés do Pará) de fissura Este tipo não é convencionalmente conhecido por Grés do Pará. E uma rocha ferruginosa formada ao longo de fissuras, fraturas, falhas, veios, clivagens, foliações, estratificações etc. É representada costumeiramente por delgadas acumulações de goethita com alumínio e goethita, depositadas paralelamente às paredes das fissuras, sempre em estruturas plásmicas bandadas, delineadas pela alternância de cores amarelas e marrons (Fig. 7).

\section{EMBASAMENTO E/OU ROCHA-MÃE Oslateritos}

da Amazônia formaram-se a partir de diferentes tipos de rochas-mães ou foram depositados sobre diferentes tipos de embasamentos (Tab. 3). As rochas-mães são de diferentes idades, do Pré-Cambriano ao Cretáceo (lateritos maturos) e do PréCambriano até o Pleistoceno (lateritos imaturos), envolvendo rochas sedimentares, metamórficas e ígneas, bem como as próprias rochas lateríticas antigas. Não causa surpresa esta grande diversidade de rochas-mães, pela vastidão da Amazônia, que ocupa grande variedade de ambientes geológicos.

Nos lateritos autóctones, a rocha-mãe é normalmente o próprio substrato dos perfis, enquanto nos alóctones, substrato e rocha-mãe podem ser totalmente diferentes. A maioria dos lateritos da Amazônia derivaram de rochas sedimentares, devido a sua grande distribuição areal, como parte das Bacias do Amazonas e Parnaíba, aflorantes desde o Mesozóico.

As regiões de lateritos bauxíticos e caulínicos da Amazônia derivaram de sedimentos cretáceos das Formações Alter do Chão e Itapecuru, enquanto sedimentos plio-pleistocênicos das Formações Barreiras e Solimões permitiram a formação apenas de lateritos imaturos.

\section{IDADE E TEMPO DE FORMAÇÃO DOS LATERITOS}

Os lateritos da Amazônia se formaram em pelo menos dois períodos distintos. Os maturos iniciaram o seu estabelecimento no Terciário Inferior (Eoceno-Oligoceno), segundo Costa (1982), Truckenbrodt et al (1982) e Costa (1984), sendo retrabalhados provavelmente no Mioceno e Pleistoceno (Kotschoubey 1984, Costa 1990, Costa et al. 1991). São do Terciá-

Tabela 3 - Rocha-mãe dos lateritos da Amazônia

Table 3 - Parent rocks of Amazon Laterites

\begin{tabular}{|c|c|c|c|c|}
\hline $\begin{array}{l}\text { TIPO DE } \\
\text { LATERITOS }\end{array}$ & ROCHA-MĀE & $\begin{array}{l}\text { SUA UNIDADE } \\
\text { GEOLOGICA }\end{array}$ & SUA IDADE & $\begin{array}{l}\text { LOCAL DE } \\
\text { OCORRÊNCIA }\end{array}$ \\
\hline BAUXITICO & $\begin{array}{l}\text { Arenitos arcoseanos } \\
\text { e argilosos } \\
\text { Rochas vulcânicas } \\
\text { Granitos } \\
\text { Metassedimentos }\end{array}$ & $\begin{array}{l}\text { Formaçōes Alter do Chão } \\
\text { e Itapecuru } \\
\text { Grupos Grão Pará, Gurupi } \\
\text { e Iricoumé } \\
\text { Suite Mapuera } \\
\text { Grupo Gurupi }\end{array}$ & $\begin{array}{l}\text { Cretáceo } \\
\text { Proterozóico Médjo a Inferior } \\
\text { Proterozóico } \\
\text { Proterozóico }\end{array}$ & $\begin{array}{l}\text { Trombetas, Mhamundá, } \\
\text { Paragominas } \\
\text { Carajás, Gurupi, Pitinga } \\
\text { Pitinga } \\
\text { Piriá, Pirocaua }\end{array}$ \\
\hline FOSFÁTICO & $\begin{array}{l}\text { Sedimentos areno-argilosos } \\
\text { Metassedimentos } \\
\text { Básica-ultrabásica } \\
\text { Alcalina-ultramáfica- } \\
\text { carbonatitica }\end{array}$ & $\begin{array}{l}\text { Não classificado } \\
\text { Grupo Gurupi } \\
\text { Grupo Gurupi } \\
\text { Não classificado }\end{array}$ & $\begin{array}{l}\text { Provavelmente Proterozóico } \\
\text { Protetozóico } \\
\text { Proterozóico } \\
\text { Proterozóico Superior }\end{array}$ & $\begin{array}{l}\text { Sapucaia, Boa Vista } \\
\text { Jandiá, Pedra Grande } \\
\text { Cansa Perna, Pirocaua } \\
\text { Itacupim, Trauira } \\
\text { Maicuru, Seis Lagos }\end{array}$ \\
\hline TITANÍFERO & $\begin{array}{l}\text { Alcalina-ultramáfica- } \\
\text { carbonatítica }\end{array}$ & Não classificado & Proterozóico Superior & Maicuru, Maraconai \\
\hline NIOBIFERO & $\begin{array}{l}\text { Alcalina-ultramáfica- } \\
\text { carbonatítica }\end{array}$ & Não classificado & Proterozóico Superior & Seis Lagos, Maicuru \\
\hline AURÍFERO & $\begin{array}{l}\text { Gnaisses } \\
\text { Filitos }\end{array}$ & $\begin{array}{l}\text { Sequiềncia Cassiporé } \\
\text { Grupo Gurupi }\end{array}$ & $\begin{array}{l}\text { Arqueano a Proterozóico } \\
\text { Inferior } \\
\text { Proterozóico }\end{array}$ & $\begin{array}{l}\text { Cassiporé } \\
\text { Aurizona }\end{array}$ \\
\hline NIQUELIFERO & Rochas ultrabásicas & Complexo Serta Azul & Arqueano & $\begin{array}{l}\text { Vermelho, Poma, Onça } \\
\text { Xingu }\end{array}$ \\
\hline MANGANESIFERO & $\begin{array}{l}\text { Metassedimentos/ } \\
\text { sedimentos }\end{array}$ & $\begin{array}{l}\text { Grupos Rio Fresco, } \\
\text { Vila Nova e Gutupi }\end{array}$ & Proterozóico Inferior & $\begin{array}{l}\text { Azul, Serra do Navio, } \\
\text { Gurupi }\end{array}$ \\
\hline $\begin{array}{l}\text { PERFIS } \\
\text { IMATUROS }\end{array}$ & $\begin{array}{l}\text { Sedimentos, granitöides, } \\
\text { Formaçōes Barteiras, } \\
\text { filitos, cherts, vulcânicas } \\
\text { ácidas, ultramáficas, } \\
\text { lateritos maturos }\end{array}$ & $\begin{array}{l}\text { Prê-cambriano ao } \\
\text { Solimōes, Pirabas e demais } \\
\text { citadas acima }\end{array}$ & $\begin{array}{l}\text { Presentes em toda } \\
\text { Pleistoceno }\end{array}$ & Amazônia \\
\hline
\end{tabular}

Para mais informações veja tabela 5 e figuras 1 e 9 
rio Inferior, também, os lateritos bauxíticos dos Escudos das Guianas (Aleva 1981), que devem ter sido formados contemporaneamente com os da Amazônia durante o estabelecimento da superfície de aplainamento Sul-Americana/Oronoque. Os lateritos imaturos se formaram durante o Quaternário (Pleistoceno), por ocasião da superfície de aplainamento Paraguaçu/Mazarini. Não há evidências de que esses processos se estenderam até o Holoceno.

Sobre o tempo de formação dos lateritos, por outro lado, existem poucas informações. Cálculos nesse sentido foram feitos por Oliveira \& Schwab (1980), a partir dos lateritos fosfáticos de Itacupim, que deram um tempo mínimo de 2,8 Ma. Aleva (1981) sugere 2,0 Ma como tempo de formação para os lateritos bauxíticos da Amazônia. Neste trabalho, estima-se que os lateritos maturos tiveram um tempo de formação de 10 a $20 \mathrm{Ma}$, até mesmo $30 \mathrm{Ma}$, como sugerem Truckenbrodt et al. (1982) e Bardossy (1983). Esse tempo de formação representa provavelmente o tempo necessário para a evolução policíclica desses lateritos. Lateritos imaturos, mais jovens devem ter sido formados num intervalo de tempo muito menor, de 0,5 a $1,0 \mathrm{Ma}$.

COBERTURAS Os lateritos da Amazônia quase sempre apresentam algum tipo de cobertura (Tab. 4). É provável que as rochas lateríticas mais antigas estejam camufladas por diversos tipos de coberturas. São poucos os exemplos de lateritos desprovidos de qualquer tipo de cobertura, a exemplo dos lateritos ferruginosos de Carajás, os fosfáticos do Gurupi e os titaníferos de Maicuru e Maraconaí. Os inúmeros lagos que cobrem hoje, parcialmente, esses corpos (Carajás, Gurupi, Seis Lagos, Maicuru, Maraconaí etc) indicam a presença provável de coberturas sedimentares já no passado, como se pode, isoladamente, observar nos registros sedimentares a base de calcários sideríticos e argilitos piritosos em Seis Lagos-AM. A cobertura mais típica dos lateritos da Amazônia está representada pela Argila de Belterra, que se estende por toda região, tanto sobre os lateritos maturos como sobre os imaturos, sob a forma autóctone ou alóctone. Essa cobertura é encontrada invariavelmente em áreas onde há densa floresta tropical, sendo mais espessa quando ocorre sobre os platôs. Sombroek (1966) descreveu este material como originário de sedimentação marinha, enquanto Truckenbrodt \& Kotschoubey (1981) sugerem uma sedimentação por fluxo de lama em clima semi-árido. A maioria dos lateritos antigos espalhados pelo mundo foram, após sua formação, recobertos por sedimentos lacustres, como calcários, turfas e argilas piritosas, como se pode concluir pêlos dados de Bardossy (1982).
INTEMPERISMO ATUAL DOS LATERITOS Existem significativas evidências de que tanto os lateritos maturos como os imaturos da Amazônia estão sob os efeitos de intenso intemperismo químico - instáveis, portanto, ao clima tropical holocênico reinante em quase toda região. $O$ produto final deste intemperismo é um latossolo equivalente à Argila de Belterra (Wolf 1972, Sombroek 1966). Localmente, ela ainda apresenta porções reliquiares da rocha-mãe laterítica (crosta ferruginosa, bauxita etc), correspondendo, assim, a um novo horizonte saprolítico (Fig. 8), derivado de lateritos antigos. Quando autóctones, esses latossolos se associam sempre com as linhas de pedras. Mas, em geral, o perfil de alteração dos lateritos da Amazônia, especialmente dos imaturos, mostra material argilo-arenoso, cinza no topo e amarelo na base, onde ainda contém relictos de esferóides ferruginosos do antigo horizonte ferruginoso. $\mathrm{O}$ desmatamento atual provoca a lixiviação do seu material fino e a concentração dos grossos, iniciando a formação de futuras linhas de pedras.

DEPÓSITOS MINERAIS ASSOCIADOS Acomplexidade geológica da Amazônia, gerando complexos tipos petrográficos, as rochas-mães dos lateritos da Amazônia, bem como a complexa evolução desses lateritos ao longo do Terciário, fizeram com que os lateritos apresentem um alto potencial metalogenético. A tabela 5 e a figura 9 dão mostras das mineralizações associadas aos lateritos da Amazônia, até hoje conhecidas. Além das jazidas de bauxita, ferro, caulinita, manganês e ouro - várias em fase de explotação organizada -, há ainda os depósitos de níquel, cromita, fosfates, estrôncio, titânio, nióbio etc, os quais tem alto potencial de conter jazidas.

Os lateritos maturos, em decorrência de seu alto grau de evolução, o que favorece o elevado grau de diferenciação química, são os mais complexos em mineralizações associadas. Lateritos imaturos são mais propícios a concentrar ouro, urânio, platina, níquel, cobre e cobalto.

CONCLUSÕES O conhecimento atual sobre lateritos na Amazônia permite concluir que os mesmos são muito importantes, não somente para o mapeamento geológico, como para a prospecção de jazidas minerais. Também são importantes porque o seu estudo está contribuindo para o entendimento da evolução geológica da Amazônia, especialmente do período pós-cretácico. As grandes jazidas da região, geralmente associadas às rochas lateríticas, foram descobertas ainda sob conhecimentos geológicos apenas gerais, o que faz supor que a região ainda tem grande potencial a ser desvendado.

Tabela 4 - Tipos de coberturas nos lateritos da Amazônia Table 4 - Types of covers of Amazon Laterites

\begin{tabular}{|c|c|c|}
\hline & TIPOS & LOCAIS DE OCORRÊNCIAS \\
\hline $\begin{array}{l}\text { Lateritos } \\
\text { Maturos }\end{array}$ & $\begin{array}{l}\text { 1. Sedimentos lacustres (argilas, carbonatos, 1. Seis } \\
\text { Lagos, Gurupi } \\
\text { turfa e pirita); } \\
\text { 2. Latossolos areno-argilosos autóctones e alóctones } \\
\text { a) amarelados } \\
\text { b) avermelhados } \\
\text { 3. Sedimentos marinhos } \\
\text { 4. Grês do Pará, lateritos imaturos, linhas de pedra }\end{array}$ & $\begin{array}{l}\text { 2.a. Paragominas, Trombetas, Pitinga, Manaus } \\
\text { 2.b. Bahia (Garajás), Maicuru, Maraconai } \\
\text { 3. Gurupi } \\
\text { 4. Gurupi, Tiracambu, Paragominas }\end{array}$ \\
\hline $\begin{array}{l}\text { Lateritos } \\
\text { Imaturos }\end{array}$ & $\begin{array}{l}\text { 1. Latossolos areno-argilosos } \\
\text { 2. Linhas de pedra/coluvião } \\
\text { 3. Aluviöes }\end{array}$ & $\begin{array}{l}\text { 1. Por toda parte } \\
\text { 2. Por toda parte } \\
\text { 3. Rondônia, Pitinga } \\
\end{array}$ \\
\hline
\end{tabular}




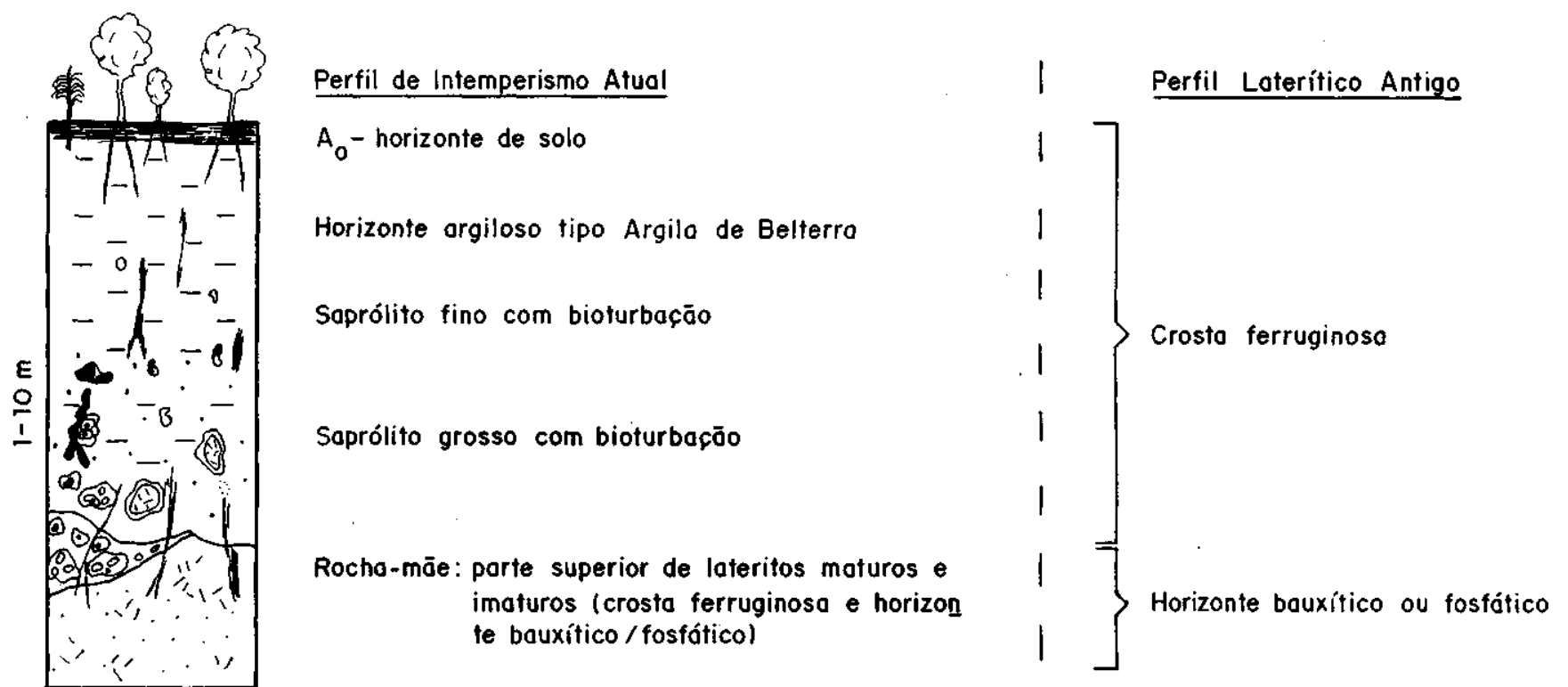

Figura 8 - Perfil simplificado da sequência de intemperismo das rochas lateríticas na Amazônia durante o Holoceno ou anteriormente

Figure 8 - Simplifíed weathering profile of Amazon laterites during the Holocene or earlier

Tabela 5 - Depósitos de minerais lateríticos mais importantes da Amazônia

Table 5 - The most important lateritic ore deposite in Brazilian Amazon region

\begin{tabular}{|c|c|c|}
\hline \multicolumn{2}{|c|}{ TIPOS DE LATERITOS } & \multirow[b]{2}{*}{ LOCALIDADE DOS DEPÓSITOS } \\
\hline $\begin{array}{l}\text { Segundo a } \\
\text { mineralização }\end{array}$ & $\begin{array}{l}\text { Segundo a } \\
\text { evolução }\end{array}$ & \\
\hline Bauxitico & Maturo & $\begin{array}{l}\text { Paragominas-PA (2), Tiracambu-MA (3) Jari/Monte Dourado-PA (7), Trombetas/Nhamundá- } \\
\text { PA (8), Pitinga-MA (4), Manaus-AM (10), Tucurui-PA (4), Piriá-PA (1), Cassiporé-AP (6), } \\
\text { Carajás-PA (5) }\end{array}$ \\
\hline $\begin{array}{l}\text { Fosfático } \\
\text { estroncifero }\end{array}$ & Maturo & $\begin{array}{l}\text { Itacupim, Cansa Perna, Jandiá, Sapucaia-Boa Vista-PA (11), Trauira e Pirocaua-MA (12), } \\
\text { Maicuru-PA (13) }\end{array}$ \\
\hline Com terras raras & Maturo & $\begin{array}{l}\text { Maicuru-PA (13), Sapucaia-PA (11), Seis Lagos-AM (14), Pitinga-AM̄ (9), Costa } \\
\text { Marques-RO (15) }\end{array}$ \\
\hline Ferruginoso & $\begin{array}{l}\text { Maturo e } \\
\text { imaturo }\end{array}$ & Carajás-PA (16), Piriá-PA (1), maioria dos lateritos imaturos \\
\hline Titanifero & $\begin{array}{l}\text { Maturo e } \\
\text { imaturo }\end{array}$ & Maraconai-PA (7), Maicuru-PA (13), Jacaré-MA (18) \\
\hline Niobífero & Maturo & Seis Lagos-AM (14), Maicuru-PA (13) \\
\hline Manganesifero & $\begin{array}{l}\text { Maturo e } \\
\text { imaturo }\end{array}$ & $\begin{array}{l}\text { Serra do Navio-AP (19), Azul-PA (20), Cumaru-PA (21), Aurizona-MA (23), } \\
\text { Bom-Fim-AM (24), Providência-RO (25) }\end{array}$ \\
\hline Niquelifero & $\begin{array}{l}\text { Maturo e } \\
\text { imaturo }\end{array}$ & Vermelho, Puma e Onça-PA (26), Quatipuru-PA (27) \\
\hline Cuprífero & $\begin{array}{l}\text { Maturo e } \\
\text { imaturo }\end{array}$ & Salobo, 1g. Bahia-PA (26) \\
\hline Caolínico & $\begin{array}{l}\text { Maturo e } \\
\text { imaturo }\end{array}$ & Felipe-AP (28), Capim-PA (29), S. Gabriel da Cachoeira-AM (30) \\
\hline Aurifero & $\begin{array}{l}\text { Maturo e } \\
\text { imaturo }\end{array}$ & Cassiporé-AP (6), 1g. Bahia, Xingu-PA (26) \\
\hline $\begin{array}{l}\text { Com resistatos: } \\
\text { - cromita } \\
\text { - cassiterita, } \\
\text { zircão, } \\
\text { xenotima, } \\
\text { columbita } \\
\text { - cassiterita } \\
\end{array}$ & $\begin{array}{l}\text { Maturo } \\
\text { imaturo }\end{array}$ & $\begin{array}{l}\text { Vila Nova-AP (31) } \\
\text { Pitinga-AM (9) } \\
\text { Rondônia-RO (32) }\end{array}$ \\
\hline
\end{tabular}

Os números entre parênteses após os nomes das localidades permitem localizá-las no mapa da figura 9 


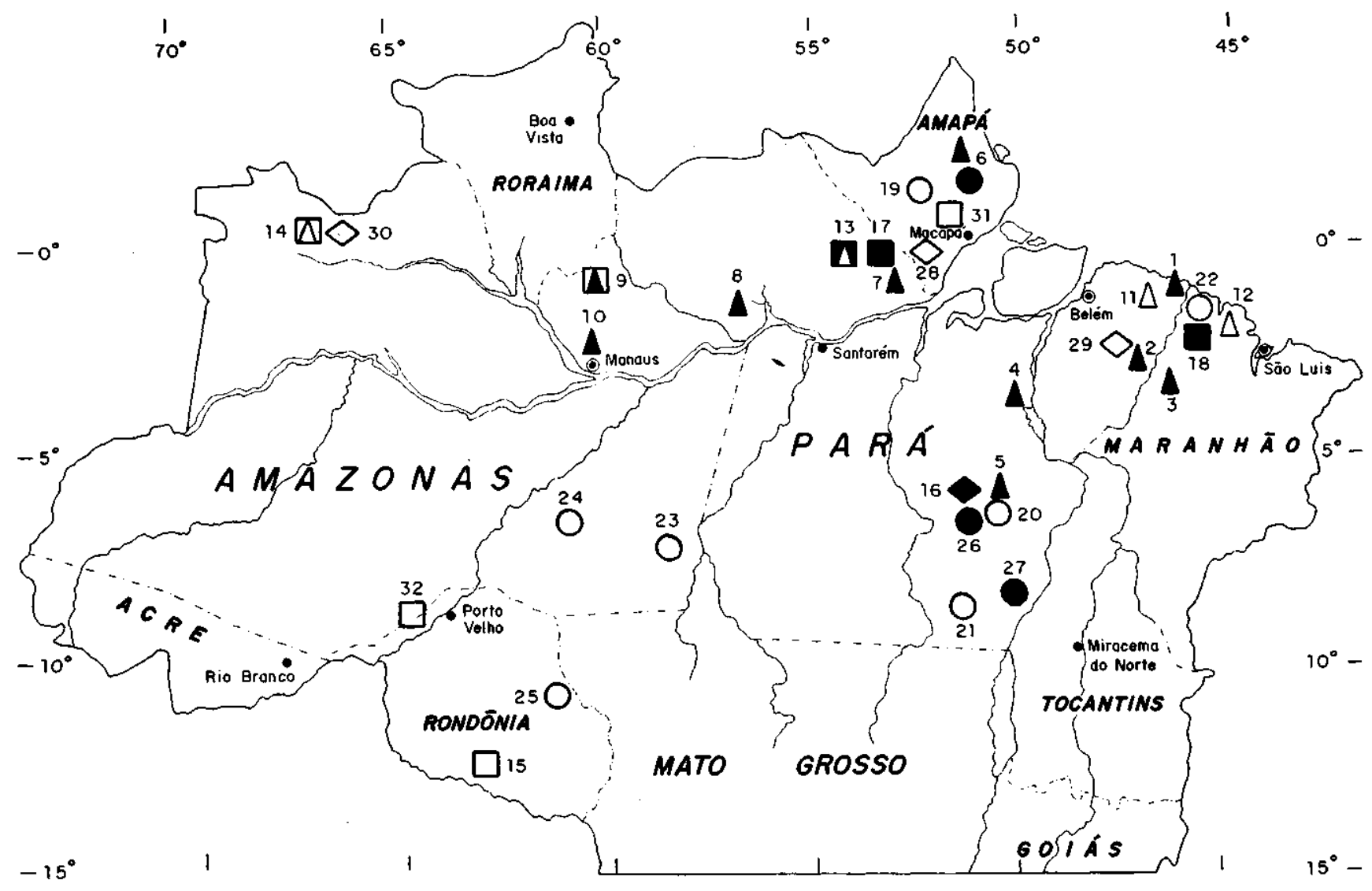

Figura 9 - Jazidas minerais lateríticas da Amazônia Brasileira. $\Delta$ - Laterito fosfático; $\Delta \mathrm{s} r, \Delta$ ETR - Laterito fosfático estroncífero elou com terras raras; $\boldsymbol{\Delta}$ Laterito bauxítico; - Laterito manganesífero; ${ }^{-C M}, \mathrm{Ni}, \mathrm{Au}$ - Laterito cuprífero, niquelífero, aurifero; $\diamond$ - Laterito caolínico; $\diamond$ - Laterito ferruginoso; - Laterito titanífero; $\square-R e s i s t a t o s(N b, \mathrm{Zr}, \mathrm{Sn}, \mathrm{ETR}, \mathrm{Cr})$ Laterito com resistato

Figure 9 - Lateritic ore deposits in Brazilian Amazon region. $\Delta$ - Al-phosphatic lateritic with $\mathrm{Sr} ;(\Delta$ srj. $\Delta$ or- $R E E ; \quad \boldsymbol{\Delta}$ bauxític; - manganesíferau; $\bullet \mathrm{Cu}, \mathrm{Ni}$, Au - bearing; $\diamond$ - kaolinic; $\diamond$-femiginous; - - titaniferous. See table 5 ; $\square$ - Resostates (Nb, Zr, Sn, REE, Cr)

A exploração geoquímica, se não souber identificar os processos que deram origem à formação dos lateritos e à sua posterior alteração intempérica, não poderá ser bem sucedida na Amazônia, pois a maioria das coberturas superficiais são a base de latossolos autóctones e alóctones, coluviões e aluviões que derivaram das rochas lateríticas durante a evolução do relevo no Cenozóico.

Os lateritos são, portanto, importantes registros geológicos, contendo significativas informações sobre a evolução do relevo, do clima, da flora, dos ambientes sedimentares, sobre a formação de colúvios e aluviões e sobre neotectônica.

Ao contrário da Austrália, onde o clima atual é árido a semi-árido, a região Amazônica é dominada por clima tropical e por uma correspondente cobertura florestal densa, e complexo sistema fluvial, extenso e caudaloso. Como resultado, os lateritos da Amazônia estão mascarados por espessos latossolos argilo-arenosos a areno-argilosos tipo Argila de Belterra e/ou por cobertura sedimentar, em vez de estarem obliterados por calcretes, silcretes, materiais gipsíticos e campos de areia, como na Austrália. Pelo fato de os lateritos na Amazônia estarem em parte recobertos, o seu mapeamento se torna difícil e os padrões de dispersão geoquímica daí resultantes são completamente diferentes daqueles de regiões como a Austrália. Desse modo, a pesquisa de lateritos na Amazônia requer técnicas um pouco diferentes daquelas aplicadas em regiões áridas e semi-áridas. Conseqüentemente, torna-se urgente incentivar as pesquisas desses materiais na Amazônia para descobrir técnicas apropriadas à pesquisa mineral em regiões como esta, com a finalidade de não incorrer nos erros do passado recente, quando foram empregadas indiscriminadamente na região e em todo país técnicas importadas.

Agradecimentos Desejo registrar em primeiro lugar o meu agradecimento à minha esposa, Walmeire Alves de Melo Costa, que me assistiu durante estes anos de dedicação aos lateritos da Amazônia. Agradeço a todos meus estudantes e colegas, que propiciaram as valiosas discussões sobre o tema. Sou muito grato ao geólogo Rômulo Simões Angélica, meu mestrando que me incentivou à montagem deste trabalho. Meus agradecimentos ao meu secretário especial Anselmo José Monteiro dos Santos durante a preparação do manuscrito e à confecção dos desenhos. Este trabalho foi de forma direta e indiretamente apoiado por CNPq, FINEP, PADCT/FINEP, DAAD, CAPES, DOCEGEO, PARANAPANEMA, UFPa, CPRM, PETROMISA e pelo governo do Estado do Acre.

\section{REFERÊNCIAS BIBLIOGRÁFICAS}

ALEVA, G.J.J. 1981. Essential differences between the bauxitic deposits along the southern and northern edges of the Guiana Shield, South America. Econ. Geol, 76:1142-1152.
ALVES, C. A.; BERNARDELLI, A.L.; BEÏSIEGEL, V.R. 1984. A jazida de níquel laterítico do Vermelho, Serra dos Carajás, Pará. In: SIMP. AMAZONICO, 2. Manaus, 1984. Anais... Manaus, DNPM. p. 339-353. 
ASSAD, R 1978. Depósitos de bauxitas na Amazônia. In: CONGR. BRÁS. GEOL., 30. Recife, 1978. Anais... Recife, SBG. v. 6, ${ }^{\mathrm{p}}$. 2511-2519.

ASSAD, R. \& BE1S1EGEL, V.R. 1978. Depósitos de bauxita na Serra dos Carajás, ïn: CONGR. BRÁS. GEOL., 30. Recife, 1978. Anais... Recife, SBG. v. 4, p. 1385-1391.

ASSAD, R. \& NETTO, A.P.A. 1976. Depósitos de bauxita de Almerim. In: CONGR. BRÁS. GEOL., 29. Ouro Preto, 1976. Anais... Ouro Preto, SBG V. 3, P. 113-115.

BANERJI, P.K. 1982. Lateritization processes - Challenges and opportunities Episodes, 3:16-20.

BARDOSSY, G. 1983. A comparison of the main bauxitic region of our globe. In: INT. SEM. ON LATERITIZATION PROCESSES, 2. São Paulo, 1982. Proceedings... São Paulo, IAG/USP. p. 15-51.

BEAUVAIS, A.; MELFI, J.A.; NAHON, D.; TRESCASES, J.J. 1987. Pétrologie du gisement latéritique manganésifére d' Azul (Brasil). Mineralium Deposita, 22:124-134.

BEISIEGEL, V. R. 1982. Distrito ferrífero da Serra dos Carajás. In: SÏMP. GEOL. AMAZ., 1. Belém, 1982. Anais... Belém, SBG/NNO. Anexo, p. $25-46$.

BERNARDELLI, A.L. 1982a. Jazida de manganês do Azul. In: SIMP. GEOL. AMAZ., 1. Belém, 1982. Anais... Belém, SBG/NNO. Anexo, p. 51-59.

BERNARDELLI, A.L. 1982b. Depósitos de níquel Jaterítico do vermelho. In: SIMP. GEOL. AMAZ., 1. Belém, 1982. Anais... Belém, SBG/NNO Anexo, p. 87-98

BERNADELLI, A.L. \& BEISIEGEL, V. R. 1978. Geologia económica da jazida de manganês do Azul. In: CONGR. BRÁS. GEOL., 30. Recife, 1978. Anais... Recife, SBG/NNO. v. 4, p. 1431-1444

BERNADELLI, A.; MELFI, J.A.; OLIVEIRA, S.M.B.; TRESCASES, J.J. 1983. The Carajás nickel deposits. In: INT. SEMINAR ON LATERITIZATION PROCESSES, 2. São Paulo, 1983. Proceedings... São Paulo, 1AG/USP. p. 107-118.

BRANDT, F. 1932. Ein neuer Typ von Elsen-Tonerde-Phosphat-Vorkommen (Maranhão, Nordbrasilien). Chemle der Erde, 7:333-425.

CHAUVEL, A.; BOULET, R.; JOIN, P.; BOCQUIER, G. 1983. Aluminium and iron oxi-hydroxide segregation in nodules of latosols developed on Tertiary sediments (Barreiras Group) near Manaus (Amazon Basin), Brazil. In: INT. SEMINAR ON LATERITIZATION PROCESSES, 2. São Paulo, 1983. Proceedings... São Paulo, IAG/USP. p. 507-526.

CORRÊA, S.L.A.; COSTA, M.L.; OLIVEIRA, N.P. 1988. Contribuição geoquímica à zona laterítica do Complexo Carbonatítico de Seis Lagos (Amazonas). In: CONGR. BRÁS. GEOL., 35. Belém, 1988. Anais.. Belém, SBG. v. 4, p. 1959-1968.

CORREAA, S.L.A.; OLIVEIRA, N.P.; SCHWAB, R.G. 1984. Alguns aspectos mineralógicos e geoquímicos da laterita niquelífera do Vermelho, Serra dos Carajás, e suas implicações genéticas. In: CONGR. BRÁS. GEOL. 33. Rio de Janeiro, 1984. Anais... Rio de Janeiro, SBG. v. 10, p. 4838-4849.

COSTA, ML. 1980. Geologia mineralogia geoquímica e génese dosfosfatos de Jandiá, Cansa Perna, Itacupim no Pará e Traúra e Pirocaua no Maranhão. Belém, 146 p. (Tese de mestrado, CG/UFPa).

COSTA, M.L. 19C2. Petrologisch-geochemische Untersuchungen zur Génese von Bauxire und Phosphat-Laterite der Region "Gurupi" (Ost-Ainazonien). Erlangen (RFA). 189p. (Tese de doutoramento. Mineralogisches Instituí, Universitát Erlangen-Nürnberg).

COSTA, M.L. 1984. A dinâmica de formação de lateritas: o exemplo do NE do Pará e NW do Maranhão. In: CONGR. BRÁS. GEOL. 33., Rio de Janeiro, 1984. Anais... Rio de Janeiro, SBG. v. 10, p. 4823-4837.

COSTA, M.L. 1985. Contribuição à geologia das lateritas do Acre^e sua importância para construção civil. In: SIMP. GEOL. DA AMAZÔNIA 2. Belém, 1985. Anais... Belém, SBG/NNO. v. 2, p. 297-311.

COSTA, M.L. 1987. Impressões geológicas colhidas na região de Carajás. UFPa/DOGEGEO. 25 p. (Rei. viagem, inédito).

COSTA, M.L. 1988a. Lateritos: geologia, mineralogia, geoquímica, génese e depósitos minerais. Belém, CG/UFPa. 120 p. (Monografia inédita).

COSTA, M.L. 1988b. Os laterítos de Rondônia. CPRM, 12 p. (Rei. téc.).

COSTA, M.L. 1990a. Lateritos e lateritização. In: CONGR. BRÁS. GEOL., 36. Natal, 1990. Anais... Natal, SBG. v. 1, p. 404-421.

COSTA, M.L. 1990b. Potencial met alogenético dos lateritos da Amazônia. In: CONGR. BRÁS. GEOL., 36. Natal, 1990. Anais... Natal, SBG. v.3, p. $1371-1385$.

COSTA, M.L. 1991. Mineralogia, geoquímica, génese e epigênese dos lateritos de Jandiá. Geochimica Brasiliensis, 4(1):85-110.

COSTA, M.L.; COSTA, W.A.M.; SÁ, J.H.S. 1978. Fosfates da região nordeste do Pará e noroeste do Maranhão. In: CONGR. BRÁS. GEOL., 30. Recife, 1978. Resumo das Comunicações... Recife, SBG. Boi. 1, p. $115-116$.

COSTA, M.L.; COSTA, W.A.M.; SCHWAB, R.G. 1980. Mineralogia das ocorrências de fosfates lateríticos do Pará e Maranhão (Brasil). In: CONGR. BRÁS. GEOL., 31. Camboriú, 19SO. Anais... Camboriú, SBG. v. 4, p. $1982-1996$

COSTA, M.L. \& SÁ, J.H.S. 1980. Os fosfates lateríticos da Amazônia Oriental: geologia, mineralogia, geoquímica e correlacão com as bauxitas da Amazônia. In: CONGR. BRÁS. GEOL., 31. Camboriú, 1980. Anais... Camboriú, SBG. v. 3; p. 1459-1472

COSTA, M.L. \& ARAÚJO, E.S. 1990. Projeto Lateritinga: um estudo geoquímico orientativo para os lateritos da Amazônia, In: CONGR. BRÁS. GEOL., 36. Natal, 1990. Anais... Natal, SBG. v. 2, p. 837-854.
COSTA, ML FONSECA, L R · ANGÉLICA, R S ; LEMOS, V.P. LEMOS, R.L. 1991. Gcochemical exploration on the Maicuru AlkalineUltramafic-Carbonatite Complex, northern Brazil. J. Geochem. Explor., (In press).

COSTA, M.L; HORBE, A.C.; HORBE, M.A.; TEIXEIRA, J.T. COSTA, W.A.M. 1988. Aregiãolaterítica-bauxíticadoPitinga (AM). In: CONGR. BRÁS. GEOL., 35. Belém, 1988.«4nais... Belém, SBG. v. 1, p. 256-270.

COSTA, M.L.; LEMOS, V.P.; VILLAS, R.N.N. 1991. Bauxite from the Carajás mineral Province. In: MELFI, J.A. \& BOULANGÉ, B. eds. Bauxite deposits of Brazil, (In press).

DENNEN, W.H. \& NORTON, H.A. 1977. Geology and geochemistry of bauxite deposits in the Lower Amazon Basin. Econ. Geol., 72:82-89.

GREIG, E.W. 1977. Trombetas and other Amazon Bauxites, Brazil. Soe. Minning Engineers, AIME. 34 p. (Preprint 77-H-92).

GROKE MGGT · PROST D · ILDEFONSE P · MELFI, J.A · DELVIGNE J.; PARISOT, J.C. 1985. Alteração dos minerais na zona supérgena da formação cuprífera do Salobo 3A (Serra dos Carajás) - localização do cobre nos produtos secundários. Rev. Bros. Geoc., 15(4):293-299.

GRUBB, P.L.C. 1979. Génesis of bauxite deposits in the Lower Amazon Basin and Guianas Coastal Plain. Econ. Geol., 74(4):735-750.

GUERRA, A.T. 1965. Formação de lateritas na Bacia do alto Purus (Estado do Acre). B. Geogr., 24(188):750-757.

HORBE, A.C. COSTA, M.L. 1990. Balanço geoquímico do perfil laterítico da Serra do Madeira, Pitinga-Am. In: CONG. BRAS. GEOL., 36. Natal, 1990. Anais... Natal, SBG. v.2, p. 855-866.

KATZER, F. 1903. Grundzüge der Geologie dês unterm Amazonasgebietes dês Staates Pará in Brasilien. Leipzig, M. Weg. 296 p.

KLAMMER, G. 1978. Reliefentwicklung in Amazonasbecken und pliopleistozáne Bewegungen dês Meeresspiegels. Zeitschr. für Geomorphologie, 22:390-416.

KOTSCHOUBEY, B. 1984. Bauxitas do Baixo Nhamundá, região do Médio e Baixo Amazonas - natureza e génese. In: CONGR. BRÁS. GEOL., 33. Rio de Janeiro, 1984. Anais... Rio de Janeiro, SBG. v. 8, p. 3926-3940.

KOTSCHOUBEY, B. 1988. Geologia do Alumínio. In: BRASIL MME-DNPM. Principais Depósitos Minerais do Brasil. Brasília, DNPM/CVRD. v.3, p. 599-619.

KOTSCHOUBEY, B. \& LEMOS, V.P. 1985. considerações sobre a origem e a génese das bauxitas da Serra dos Carajás. In: SIMP. GEOL. DA AMAZÔNIA, 2. Belém, 1985. Anais... Belém, SBG/NNO. v. 3, p. 48-61.

KOTSCHOUBEY, B; MENEZES, L.A.A ; TRUCKENBRODT, W. 1984. Nature et evolution dês bauxites du secteur de Jabuti-Ipixuna (distric de Paragominas, Etat du Pará, Brasil). In: CONGR. NAT. SOC. SAV, 109. Dijon, 1984. Sciences... Dijon. fase. 1, p. 335-345.

KOTSCHOUBEY, B. \& TRUCKENBRODT, W. 1981. Evolução poligenética das bauxitas do distrito de Paragominas-Acailândia (Estados do Pará e Maranhão). Rev. Bros. Geoc., 11(3): 193-202.

KRONBERG, B.I.; COUSTON, J.F.; STILIANIDI FILHO, B.; FYFE, W.S NASH, R.A.; SUGDEN, D. 1979a. Minor element geochemistry of Paragominas bauxites, Brazil. Econ. Geol., 74:1869-1875.

KRONBERG, B.I.; FYFE, W.S.; COUSTON, J.F.; STILIANIDI, F, B.; McKINNON, B.J.; NASH, R.A. 1982. Model for bauxite formation: Paragominas (Brazil). Chem. Geol, 35(3/4):311-320.

KRONBERG, B.I.; FYFE, W.S.; LEONARDOS, D.H.; SANTOS, A.M $1979 \mathrm{~b}$. The geochemistry of some Brazilian soils:. element mobility during intense weathering. Chem. Geol., 24:211-229.

LEMOS, V.P. \& COSTA, M.L. 1987. Partição dos terras raras nos lateritos fosfáticos de Maicuru-PA. In: CONGR. BRÁS. GEOQUÍMICA, 1 Porto Alegre, 1987. Anais... Porto Alegre, SBGq. v. 1, p. 83-102.

LEMOS, V.P. \& VILLAS, R.N.N. 1983. Alteração supergênica das rochas básicas do Grupo Grão-Pará - implicações sobre a génese do depósito de bauxita de N5. Serra dos Carajás. Rev. Bros. Geoc., 13(3): 165-177.

LIMA, W.N. \& REYMÀO, M.F.F. 1983. Estudo termodinâmico teórico e aplicado às alteracões de hidroxi-fosfatos naturais: fosfates lateríticos de Jandiá (PA) e Pirocaua (MA). Rev. Bros. Geoc., 13(1):41-51.

LUCAS, Y. 1989. Systemes pedologiques en Amazonie Brasilienne. Equilibres, desequilibres et transforinations. Poltiers 159 p. (Tese de doutoramento, Université de Poltiers).

LUCAS, Y.; KOBILSEK, B.; CHAUVEL, A. 1989. Structure, génesis, and present evolution of Amazonian bauxites developed on sediments. In: INTERN. CONG. ICSOBA 6, Poços de Caldas, Brazil, 1989. Proceedings... Travaux, ICSOBA. 22:81-94.

OLIVEIRA, N.P. \& SCHWAB, R.G. 1980. Itacupim: um exemplo da influência do fósforo sobre o desenvolvimento de perfis lateríticos. In: CONGR. BRÁS. GEOL., 31. Camboriú, 1980. Anais... Camboriú, SBG. v. 1, p. 184-196.

OLIVEIRA, C.M.; FONSECA, L.R.; OLIVEIRA, N.P. 1988. A laterita titanífera de Maraconaí (PA). In: CONGR. BRÁS. GEOL., 35. Belém 1988. Anais... Belém, SBG. v. 1, p. 271-285.

SCHELLMANN, W. 1980. Considerations on the defmition and classification of laterites. In: INT. SEMINAR ON LATERITIZATION PROCESSES, 1. Trivandrum, 1979. Proceedings... Trivandrum, Oxford \& Ibh. p. 1-10.

SCHWAB, R.G.; COSTA, M.L.; OLIVEIRA, N.P. 1983. Ueber die Entwicklung von Bauxiten und Phosphat-Lateriten der Region Gurupi (Nordbrasilien). Zbl Geol. Palãont., 1(3/4):530-580.

SCHWAB, R.G.; OLIVEIRA, N.P. CORRÊA, S.L.A. 1985. The nickel laterites of Serra dos Carajás (Área Vermelho). Zbl. Geol. Paláont., 1:99-111. 
SCHWAB, R.G.; HEROLD, H.; COSTA, M.L.; OLIVEIRA, N.P. 1989. The formation of aluminous phosphates through lateritic weathering of rocks. In: BALASUBRAMANIAM et al. eds. Weathering: its Products and Deposits. Atenas, Theophrastus. v. 2, p. 369-386.

SHAW, E.W.; WRIGTH, W.H.; DARNELL J. 1925. The mineral resources of Maranhão, Brazil. Econ. Geol, 20:929-932.

SIQUEIRA, N.V.M. \& LIMA, W.N. 1982. Estudo geoquímico de alterações e distribuição dos elementos em perfil laterítico desenvolvido sob influência do fósforo - Pirocaua (MA). In: CONGR. BRÁS. GEOL. 32. Salvador, 1982, Anais... Salvador, SBG. v. 5, p. 1991-2001.

SOMBROEK, W.G. 1966. Amazon soils. A reconnaissance ofthe soils ofthe Brazilian Amazon region. Wageningen, Centre for Agri. 292 p. (Publ. Document).

SOMBROEK, W.G. \& CAMARGO, M.N. 1983. Groundwater laterite and ironstone soils in Brazil, with examples from the Amazon Region. In: INT. SEMINAR ON LATERITIZATION PROCESSES, 2. São Paulo, 1982. Proceedings... São Paulo, IAG/USP. p. 541-552.

TOWSE, D. \& VINSON, P. 1959. Lateritas aluminosas do Baixo Amazonas. Eng. Min. Met., 30(177):133-135.

TRUCKENBRODT, W. 1982. Alguns aspectos microfaciológicos das bauxitas na parte leste da região Amazônica. In: CONGR. BRÁS. GEOL., 32. Salvador, 1982. Anais... Salvador, SBG. v. 2, p. 695-701.

TRUCKENBRODT, W. \& KOTSCHOUBEY, B. 1981. Argila de Belterra Cobertura terciária das bauxitas amazônicas. Rev. Bros. Geoc., 11(3):203-208

TRUCKENBRODT, W.; KOTSCHOUBEY, B.; GÓES, A.M. 1982 Considerações a respeito da idade das bauxitas na parte leste da região
Amazônica. In: SIMP. GEOL. DA AMAZÔNIA, 1. Belém, 1982. Anais... Belém, SBG/NNO. v. 1, p. 201-209.

VALARELLI, J.V. 1967. O minério de manganês da Serra do Navio, Amapá. São Paulo (Tese de Doutoramento, FFCL/USP).

VALARELLI, J.V; BERNARDELLI, A.; BE1SIEGEL, V.R. 1978. Aspectos genéticos do minério de manganês do Azul. In: CONGR. BRÁS. GEOL., 30. Recife, 1978. Anais... Recife, SBG. v. 4, p. 1670-1679.

VALETON, I. 1972. Bauxites. Developments in Sou Science 1. Amsterdam, Elsevier. $226 \mathrm{p}$.

VEIGA, M.M. 1984. Propriedades geoquímicas da ligação cobre-óxidos hidratados de ferro: um estudo do minério alterado do Salobo 3A, Carajás-PA. Rio de Janeiro, (Dissertação de mestrado, UFF).

VEIGA, A.T.C.; BRAIT FILHO, L.; OLIVEIRA, C.A.C. 1985. Geologia da Província aurífera do Cassiporé-Amapá. In: SIMP. GEOL. AMAZÔNIA, 2. Belém, 1985. Anais... Belém, SBG/NNO. v. 3, p. 135-146.

VIEIRA, M.A.M.; GUIMARÃES, I.G.; AMARAL, M.A.M. 1984. Perfil de alteração de xistos da jazida de cobre Salobo 3A-Pará. In: S YMPOSIUM AMAZONICO, 2. Manaus, 1984. Anais... Manaus, DNPM. p. 313-326

WOLF, F.A.M. 1972. Bauxita na Amazônia. Belém, DNPM. 46 p.

MANUSCRITO A608

Recebido em 06 de julho de 1989

Revisão do autor em 08 de abril de 1991 Revisão aceita em 07 de maio de 1991 